The Profession of Social Work and the work of Social Assistance: Partners or the parting of ways?

A political economic perspective on the factors that have influenced the relationship between the profession of social work and the field of municipally administered social assistance programs in Ontario

by

Alison Tutak, BA, BSW

A Thesis submitted to the Faculty of Graduate Studies and Research in partial fulfillment of the requirements for the degree of

Master of Social Work

School of Social Work

Carleton University

Ottawa, Ontario

May 2010

CCopyright, 2010

Alison Tutak 
Library and Archives

Canada

Published Heritage

Branch

395 Wellington Street Ottawa ON K1A ON4

Canada
Bibliotheqque et

Archives Canada

Direction du

Patrimoine de l'édition

395 , rue Wellington

Ottawa ON K1A ON4

Canada
Your file Votre référence

ISBN: 978-0-494-68630-0

Our file Notre référence

ISBN: 978-0-494-68630-0
NOTICE:

The author has granted a nonexclusive license allowing Library and Archives Canada to reproduce, publish, archive, preserve, conserve, communicate to the public by telecommunication or on the Internet, loan, distribute and sell theses worldwide, for commercial or noncommercial purposes, in microform, paper, electronic and/or any other formats.

The author retains copyright ownership and moral rights in this thesis. Neither the thesis nor substantial extracts from it may be printed or otherwise reproduced without the author's permission.
AVIS:

L'auteur a accordé une licence non exclusive permettant à la Bibliothèque et Archives Canada de reproduire, publier, archiver, sauvegarder, conserver, transmettre au public par télécommunication ou par l'Internet, prêter, distribuer et vendre des thèses partout dans le monde, à des fins commerciales ou autres, sur support microforme, papier, électronique et/ou autres formats.

L'auteur conserve la propriété du droit d'auteur et des droits moraux qui protège cette thèse. $\mathrm{Ni}$ la thèse ni des extraits substantiels de celle-ci ne doivent être imprimés ou autrement reproduits sans son autorisation.
In compliance with the Canadian Privacy Act some supporting forms may have been removed from this thesis.

While these forms may be included in the document page count, their removal does not represent any loss of content from the thesis.
Conformément à la loi canadienne sur la protection de la vie privée, quelques formulaires secondaires ont été enlevés de cette thèse.

Bien que ces formulaires aient inclus dans la pagination, il n'y aura aucun contenu manquant. 
The undersigned recommend to the Faculty of Graduate Studies And Research acceptance of the thesis

\section{The Profession of Social Work and the work of Social Assistance: Partners or the parting of ways?}

A political economic perspective on the factors that have influenced the relationship between the profession of social work and the field of municipally administered social assistance programs in Ontario

Submitted by Alison Tutak, BA, BSW

in partial fulfillment of the requirements for

the degree of Master of Social Work

Therese Jennissen

Thesis Supervisor

Hugh Shewell

Director, School of Social Work

Carleton University

$\frac{\text { May } 2010}{\text { Date }}$ 


\begin{abstract}
This research evaluates the historical relationship between university educated social workers, the profession of social work and the delivery of municipal social assistance in Ontario.

Through the use of a political economy framework, the thesis argues that social assistance work is generally devalued work and that the functions of social work have been significantly eroded from the work of social assistance. Social assistance work has increasingly become de-professionalized with little attention paid to the importance of assisting social assistance recipients with other aspects of their usually extremely complicated lives.
\end{abstract}

The findings of the research suggest that for university educated social workers the path to professionalization has resulted in the abandonment of social assistance work. As social work strives to legitimate itself as a profession in a market driven economy, it has tended to move away from working with the impoverished. The stigma endured by social workers in social assistance resembles the stigma faced by the clients of social assistance.

The thesis contributes to our understanding of the complex dynamics between social work and social assistance; it is a relationship that requires serious attention by the profession as poverty appears to be increasing and the lives of the impoverished become increasingly perilous. 


\section{Acknowledgements}

The popular adage that "it takes a village to raise a child" can be likened to the community of support that I received to undertake and complete this thesis. Foremost I would like to thank my thesis supervisor Therese Jennissen who has provided invaluable guidance, support, time and patience throughout. I am very grateful for the expertise and interest that Therese took in my topic and the encouragement she offered to coach me to completion. In addition, I would like to thank Cecilia Taiana for giving her time and offering direction as the second reader.

The work of this thesis was enriched substantially through the key informant interviews. I would like to extend my sincere thanks to interview participants; Bob McNorgan, Dick Stewart, Hugh Drouin, John Stapleton, Mike Schuster and Allan Moscovitch for the sharing of their rich experiences, insights and perspective. Their contributions were not something that could ever be found in a textbook and their passion and interest in the field of social assistance were both enlightening and infectious.

The patience, love and encouragement of my husband, Greg, has made it possible for me to have undertaken and achieved my educational pursuits over the past fifteen years. To my father who always has unconditionally supported me and also to the memory of my mother which has provided those gentle nudges to me along the way. Finally, my true inspiration, every day of my life is my daughters Adrianna and Ruth. Through them I see that nothing is impossible and their unconditional love and acceptance makes every day a little bit brighter than the day before. 


\section{Table of Contents}

I. Chapter One: Introduction and Research Question 1

II. Chapter Two: Methodology 7

III. Chapter Three: Literature Review 10

A. The Field of Social Assistance $\quad 10$

B. Social Work as a Profession 17

IV. Chapter Four: Theoretical Perspective 35

V. Chapter Five: The Early Years of Social Assistance (1920-1944) 50

A. Friendly Visiting and Charity 50

B. The Stock Market Crash and the Great Depression 53

C. The Struggle: Unemployment and Poverty 60

D. The Role of Social Workers 61

VI. Chapter Six: Post-War Reconstruction (1945-1973) 64

A. The War and its Aftermath 64

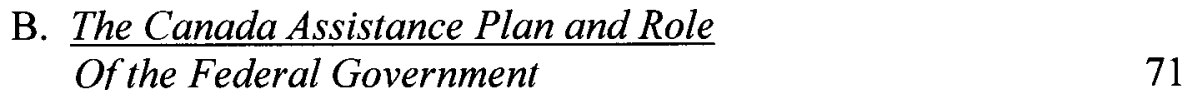

C. The Role of Social Workers

VII. Chapter Seven: Social Assistance in Ontario (1973-1976) 84

A. The Federal Provincial Social Security Review

B. Ontario: The 1970's $\quad 87$

C. The Liberal Years $\quad 87$

D. The Rae Days 90

E. The Role of Social Workers 92

VIII. Chapter Eight: Social AssistanceModern Day (1995-2009) 95

A. The Commonsense Revolution 95

B. The End of the Canada Assistance Plan 100

C. The Municipal Reorganization of Social Assistance 101

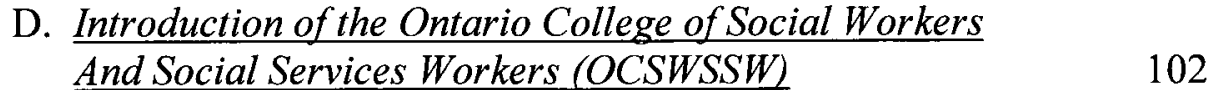

E. Organizational Culture 104

F. Technology and Social Assistance 105

G. The Dual Purpose of Social Assistance 108

H. The Role of Social Workers 110 
IX. Chapter Nine: Conclusions 115

$\begin{array}{lll}\text { X. Appendices } & 124\end{array}$

$\begin{array}{ll}\text { XI. Bibliography } & 133\end{array}$

A. Books, Journals and Government Documents

B. Key Informant Interviews 141

C. Web Based References 141 


\section{List of Appendices}

I. Appendix A: Definitions............................................. 124

II. Appendix B: Abbreviations...................................... 125

III. Appendix C: Letter of Introduction..................................126

IV. Appendix D: Premiers of Ontario and Prime Ministers of Canada .........128

V. Appendix E: Open-Ended Interviews: Discussion Probes..................130

VI. Appendix F: Letter of Ethics Permission..............................132 


\section{Chapter One: Introduction and Research Question}

The secular social work profession developed in Canada in the mid-1920s with the establishment of the Canadian Association of Social Workers (CASW). It was the early pioneers in social work that laid the foundation for a profession that would promote a collective conscience for the well-being of all Canadian citizens. They would later assist governments in constructing programs and services that became the foundation of the modern welfare state.

The secular social work profession replaced the Charity Organization Societies (COS) which was present in Canada in the 1880s and 1890s. The COS originated in London, England and their philosophy for dealing with the poor was later transported to the USA and Canada. The COS were based in Christian morality that viewed "relief" as something that should be available only to the worthy poor and only if it did not interfere with the work ethic. The COS put into place "friendly visitors" who typically were women from middle class backgrounds whose jobs involved mentoring and teaching the poor the benefits of hard work, thrift and cleanliness. The early belief that financial relief to the poor caused pauperism, coupled with the concern that many other churches and charities were duplicating their efforts and providing the poor with too much relief, the COS organized the giving of relief by neighbourhoods to reduce the potential for duplication. The three key goals of the COS included support to people to become self sufficient and moral, to understand the bonds of obligation between the classes and to control the giving of charity within the community (Wills, pg.14). 
The settlement house movement began in Canada in 1902 when the first settlement house, Evangelia House was established in Toronto. The approach of the settlement houses did not focus on the provision of charity as was done by the COS. Instead settlement houses worked at "fostering hegemony of middle class ideals, values and culture" (James, 1998, pg.49). The settlement house workers offered such services as job training, recreational opportunities, group work and they were active in advocacy work. Cathy James, a scholar of the settlement house movement, identified that their stance on religion was unique with most of their funding coming from ecclesiastical sources, yet the Canadian national settlement associations requested their members to be non-denominational (James, 1998, pg. 50). In 1910, additional settlement houses began to be created and by 1920 there were thirteen settlement houses in Canada. The workers in the settlement homes made important contributions to social work through their group work and community organizing activities (Jennissen and Lundy, 2006, pg.2). The settlement house movement was at its peak in Canada from 1910 until World War I, and some settlement houses continued until 1930.

Throughout the history of social work one consistent concern has been over the economic and material welfare of people. While the early versions of social work used extremely limited and circumscribed approaches for dealing with poverty (i.e. COS); the post war welfare state era sought broader and more comprehensive strategies that included the involvement of various levels of the state. Despite this broader and more comprehensive approach to addressing poverty, the principles underlying the COS were not entirely absent from more modern approaches to addressing poverty. This early and clear 
involvement of social workers in social assistance will form the baseline for determining the trajectory of their involvement.

One of the social programs that is part of our Canadian Welfare state is social assistance and while administered inconsistently across Canada it serves the most impoverished of our society. In 2010 the original three goals of the COS are still evident in the social assistance program of Ontario. Despite the original intentions and the significant work of early social workers, social assistance today is still characterized as the program of last resort, a program that serves the poor. Social Assistance continues to be regarded suspiciously by members of society, politicians, and the media and in some cases it is denounced outright. In October 1995 CBC reporter Denise Harington aired a story about David Tsabouchi (then Minister of Community and Social Services) who publicly suggested that social assistance recipients could adjust to the recently reduced rates of social assistance by "haggling with grocery stores for lower prices on dinted tuna". I was a social assistance worker at the time in Ontario and many of us working in the field were outraged by such comments, but the reality was that social assistance was entering a new era, a conservative era. The Harris conservative government moved briskly to cut the social assistance rates by $21.6 \%$ and implement program changes that saw tighter restrictions on rules for co-residency and an enhanced effort to reduce fraud to mention a few. The Conservative government also brought in the new Ontario Works Act in 1997 to replace the former General Welfare Assistance Act and in 1996 new technologies were implemented to support the new Ontario social assistance system: Ontario Works. 
For the past eighteen years I have worked as a social worker in the field of municipal social assistance. Specifically, I worked in the areas of direct client service, employment counselling, policy development, community development and management. Over the years I have observed that few of my co-workers, both within my place of employment as well as peers in other municipalities have not had university degrees specific to the field of social work. Is this evidence that social work professionals are not required in the administration of social assistance? Historically social workers have had an important influence in the provision of social assistance as well as the development of social assistance policies and programs.

Cassidy (1943), Struthers (1983), Jennissen and Lundy (2010) and Woodroofe (1966) have all documented the significant role of social work in the development and administration of social assistance, particularly in the era from 1920-1960. In an article in The Social Worker in 1959, Jean Grant underscores the centrality of social assistance in the evolution of the profession:

There is challenge in public welfare because of the risk, the implications for salvaging human resources, and the rewards. It was this spirit of challenge which gave original impetus to the profession of social work. Are social workers losing this spirit today? (Grant, pg.7)

Is the profession of social work still present in social assistance? If not, why not? Personal experiences have led me to believe that social work as a profession is underrepresented in the field of social assistance. This thesis is directed towards exploring this issue further. If social workers are no longer involved in the field of social assistance, what does this mean both to the recipients of social assistance, to the field of social assistance and to the social work profession? 
To assist in understanding social workers' participation in social assistance, and guided by a political economy perspective, there are three specific questions that the thesis seeks to answer:

- What have been the ideological shifts and corresponding impacts upon social work and its influence and participation in social assistance in Ontario?

- How have the political and economic realities within Ontario influenced the profession of social work and professional social workers in the field of social assistance?

- What is the relationship between social assistance and the profession of social work?

The focus of the research is to examine the various periods of time from 1920 to the present. An important benefit of examining social assistance historically is that it will unearth the multiple influences upon both the field of social assistance and the profession of social work and demonstrate the changes that have occurred over time. This time period, moreover, covers the initiation of the professional association (CASW) in Canada, the Great Depression, the coming of the welfare state, its growing pains and its milestone developments. The period from 1992 until present is representative of my personal experiences as a social worker in social assistance.

As a result of the historical evolution of social assistance in Canada, it is important to examine the Federal, Provincial and municipal roles in the funding and delivery of social 
assistance. However the thesis will focus more closely on the province of Ontario and the uniqueness of municipal social assistance delivery. Ontario has a unique social assistance system that is both municipally delivered and cost shared with the Provincial government. 


\section{Chapter Two: Methodology}

Three main methodological approaches were employed in this thesis. First was a review of literature relevant to the thesis topic. This includes secondary sources on the history and development of the Canadian welfare state, political economic theory and the history of the profession of social work. The second methodological approach is an analysis of the changes to the social assistance program over the decades. The original intention of this second approach was to analyze relevant government documents and reports. This analysis was undertaken, however it did not yield the data that would inform the research questions of this thesis. The government documents that were available and analyzed were largely from the period of 1985-1995 and many were recommendation reports as opposed to documents linked to policy and program changes. The value of the documents that were accessed was significant in their contribution to understanding the history of social assistance, but they did not lend themselves to any discourse analysis that could meaningfully inform this thesis.

Third, was the series of qualitative interviews with social assistance Administrators / Commissioners and academics that have worked or are currently working in social assistance in Ontario. The interviews provided first hand accounts, insights and perspective on the field of practice, the implementation of policies that have influenced the political realities of social assistance and the recruitment and retention of social workers in the field. This invaluable data filled in some of the gaps that I was not able to collect from government records and secondary manuscripts alone. 
With the intent of soliciting a rich historical perspective I sought interview participants who have had a significant length of tenure and that have direct experience and insight into the political and program changes of social assistance over the past several decades. Interview probes (Appendix E) were prepared with the intent to direct, supplement and give some structure to the interview but not to limit the sharing of thoughts and perspectives. Not all interview participants were educated specifically in the profession of social work which was advantageous because it provided a broader view of the issues being explored in this thesis.

The recruitment of participants for the interviews was done through personal contacts and "word of mouth" through professional affiliations. The first two interviews were completed with retired social assistance administrators, both of whom had lengthy tenures in their respective roles. The first was Bob McNorgan, retired Administrator from the City of London, Ontario. McNorgan was hired by the City of London in 1978 as a front line caseworker for welfare and in 1981 he accepted a management role. Dick Stewart began work with the City of Ottawa Social Welfare Department in 1969 as a caseworker. Stewart took on the role of Commissioner of Social Services for the Regional Municipality of Ottawa in 1993 until his retirement in 2002. Hugh Drouin is the current Commissioner of Social Services for the Regional Municipality of Durham and has held this role since 2003. Drouin is educated in social work and recruits social workers for various positions in his agency. Mike Schuster is currently the Commissioner of Social Services for the City of Waterloo and was selected to participate due to the fact that his region has a specialized social work unit. Allan Moscovitch is a current professor at 
Carleton University in the Department of Social Work and Moscovitch contributed through his work as an academic and his participation and leadership on government committees and reports to transform social assistance. John Stapleton is a former Senior Policy Analyst of 28 years, with the Ministry of Community and Social Services in Ontario. Stapleton offers not only his past tenure with the Ministry but his continued academic contributions through articles, lecturing and community involvement. 


\section{Chapter Three: Literature Review}

The research for this topic is based in English Canadian literature in addition to selected material from Britain and the U.S.A. in the broad areas of social work history and social assistance. The literature review focuses on historical material that assists in setting the general context for the role that social workers have had in the development of the Canadian welfare state and specifically their role in the area of social assistance. The review then focuses more specifically on the role of social workers in social assistance in Ontario.

\section{The Field of Social Assistance}

In 1961 a book titled Public Welfare: Time for a Change by Elizabeth Wickenden and Winnifred Bell was published. It is a report based on the author's work on "The Project on Public Services for Families and Children" that was sponsored by The New York School of Social Work of Columbia University in the United States (USA). While the research pertains to the United States specifically it is relevant to Canada. In 1959-1961 the researchers found that $98 \%$ of the staff administering welfare / pubic assistance had little or no professional training in social work. What is interesting is that when the researchers spoke with social welfare leaders who were involved in administration of welfare, they iterated that the goal of social assistance included the strengthening of family life and maximizing self support, coupled with the acceptance that these activities belong to the field of social work. The apparent contradiction that the research uncovered is that the goals of social assistance are consistent with the goals of professional social work, yet professional social workers were not commonly employed in the area of social 
assistance. This research suggests that administration of social assistance by social workers is accepted in welfare agencies and is seen as being in the purview of social work; thus work to be performed by social workers. However, the findings of Wickenden and Bell are that university educated social workers are not generally hired for this work.

The absence of university educated social workers in the delivery of social assistance is explained by two key factors according to Wickenden and Bell. The first is what the authors regard as insufficient community concern for, and financial investment in the qualifications and training of public welfare personnel. Second, the lack of federal funds to support social work education is seen as a factor contributing to the dearth of social workers in social assistance. Additionally this period of time in history saw many women departing the workforce to work in the home and with social work practice dominated by women, this may have affected those seeking social work education. Irving and Daenzer identify the 1950 s as a time that the profession suffered from an identity and survival crisis. They suggest that the reduced enrollment in schools of social work as well as the expanding employment options available and decreased educational funding led to shortages of social workers. They note that:

Public welfare casework was conducted by social workers alongside lay persons with members of both groups bearing the title of social worker. (Irving \& Daenzer in Riches and Ternowetsky, eds, 1991, pg.280)

The availability of literature specific to the role of social workers in the field of social assistance has in general been sparse, with the exception of the 1960s and into the early 1980s. There were several social work journal articles written on this topic during this time period on the very specific topic of social work and its role in the field of social 
assistance. The first of these articles appeared in 1959 in the journal entitled The Social Worker in which author Jean Grant emphatically insists that the delivery of social assistance is indeed the work of professional social workers. Grant's article has a defensive tone that may be reflective of the era. She goes as far as to suggest that social workers who have the knowledge of the needs of a community have a responsibility to work in the field of social assistance. The following quote characterizes Grant's passion on this topic:

\begin{abstract}
Every social welfare program to have substance must be recognized by the community as meeting needs which legitimately require support from tax or organized voluntary sources. The implications of this fact would appear to be overlooked by social workers when the demand for increased means to provide specialized services is based on the identification of the need...Social Work ideals are admirable but unless they are balanced in relation to the limits set by the community through legislation and by fund goals there is danger of jeopardizing gains and ultimately standing in our own light having convinced no one but ourselves of the value of our work (Grant, 1959, pg.8).
\end{abstract}

In the article Grant alludes to what she considers a basic fact, that the social work profession considers the field of social assistance to be its bailiwick but in spite of this the profession functions as an "absentee landlord". Grant warns that the profession of "social work may lose public welfare" (Grant, 1959, pg.9). The fact that this risk was identified in 1959 , raises the question as to why the profession did not stand up to the challenge of taking hold of this important aspect of its work? The answer may in part be due to conflicting ideas within both the field and the profession.

In 1960, writer Swithun Bowers wrote an article entitled "The Future of Social Work" in the journal The Social Worker. Bowers presents the field of social assistance in a very different context from Grant. He criticizes the profession of social work for trying to be all things to all people over the course of its history and suggests that it needs to define 
itself more clearly to bring credibility to the profession. He criticizes those that believe that any helping role with people requires a social worker. In Bowers' attempt to establish what he feels are the boundaries of defining the social work profession he speaks specifically to the field of social assistance and denounces it outright:

In the public assistance agency it is not appropriate to use social work competence to deal with economic problems or even to make eligibility studies for economic assistance. This task certainly requires interviewing skill and the ability to relate to people in such a way as to help them bring out the relevant facts, but these do not make it a social work task.....it is true that a theoretical case may be made that economic need inevitably brings some disruption to role performance, but when adequate economic assistance is available social functioning usually returns to a relative normality (Bowers, 1959, pg.34).

The suggestion that additional money would rectify the enormous ails of those receiving social assistance is controversial and accepting or disproving this stance will not be undertaken in the work of this thesis. The dichotomy between Grant and Bowers is a reflection of the struggle to define the profession of social work, what it included, what it did not include and where it would go into the future. In 1962, Grant wrote another article for The Social Worker entitled "Public Assistance and Casework" and here she speaks to exactly why the work of social assistance belongs within the realm of social work:

The income maintenance programs receive these people at the breaking point where survival is dependent on outside help. This is a vital point inasmuch as the expressing of the problem implies a request for aid in the solution of it. Is the applicant entitled only to the help he requests-money for food and rent - or is he entitled to the help he needs? (Grant, pg.9)

Grant argues that through casework performed in social assistance, clients are entitled to help that extends beyond the provision of food and rent money. She suggests that dependency upon public assistance often characterizes greater underlying issues - issues that require professional assistance. These issues whether they occurred in 1962 or 2010, include such circumstances as homelessness, illiteracy, abuse, struggles around sexual 
orientation, mental health issues, single parenthood and addictions. Every one of these issues in its own right is given particular attention by professionals in social work today. For example there are community outreach workers that work with the homeless, abuse counselors that work with both the abused and the abuser, addictions counselors that work with the population with various addictions and so on. The question remains, are these people given the same or equal amounts of assistance when they surface en masse in the doors of a social assistance office? Poverty is directly linked to these other issues; while authors may debate whether poverty's relationship with other social issues is causal or symptomatic, there is little doubt that the relationship is real. If social assistance is merely looked at as the provision of basic needs and is staffed with clerical administrative staff it misses the opportunity to serve the client in a holistic manner and this action betrays some of the earliest functions of the social work profession.

Amy Leigh in an article titled Viewpoint published in the journal The Social Worker in 1964 , comments on the necessity to distinguish between social work and casework. Leigh refers to the longstanding and central discussion between the field of social assistance and profession of social work. Clearly, there was a tension in the $1960 \mathrm{~s}$ between the more active social work components of social assistance, and the more mechanical aspects of filling out forms. Leigh offers the following comment:

To ensure that the skills of graduate social workers are not wasted in jobs that can be done adequately by less qualified staff is receiving a good deal of attention these days. This problem has special application in the public welfare field. It is indeed difficult to decide at the outset which family will need the services of a trained social worker, and equally difficult to separate the filling out of forms from the "service" which is to be given to the families involved. Social Workers seem to have decided that the filling out of forms is beneath them; not the forms for adoption or the placement of a child, but forms which bring much-needed financial assistance to families in distress". (Leigh, pg. 38) 
She maintains that the Federal government needs to set standards for social assistance and that the provincial governments need to set the same for municipal departments. Provincial governments should also help municipalities with funding to carry out quality programming. She notes that in the mid 1960 s that there was a great shortage of professional social workers in public welfare agencies. Leigh notes that many municipal officials were willing to employ trained social workers, but this did not always correspond to the work preferences of social workers which may have been influenced by such factors as pay and type of work. She suggests that this is a challenge that the profession cannot afford to ignore.

These articles leave the impression that during the 1960s the demand for professional social workers in the field of social assistance may have been more about social worker's reluctance to work in the areas of social assistance and less about the social service field's reticence to hire them. One issue may be the reluctance on behalf of social workers themselves and a profession unsure of its desire to claim this field of service versus the actual administration of social assistance not wanting social work to enter. Indeed the supply of trained social workers has also affected this reality, but it is only a small piece of the broader issue.

In her book No Car, No Radio, No Liquor Permit (1998), Margaret Jane Hillyard Little focuses on the plight of sole support mothers and the welfare system in Ontario between 1920-1997. Little notes that beginning in 1965, governments promised the elimination of poverty and discrimination against the poor and that the introduction of the Canada 
Assistance Plan (CAP) in 1966 marked the beginning of welfare reform. In the years to come, these promises were not realized as tighter eligibility requirements were placed upon families, hiring freezes were placed upon social workers in the field and new welfare fraud investigators were hired (Little, 1998, pg.160, 163). Little's work may highlight the reasons why the welfare system and social workers evolved over time to part ways.

Allan Moscovitch's article "Social Assistance in the New Ontario" (Ralph, Regimbald and St. Amand (eds), 1997) discusses the introduction of CAP, specifically that it was designed to include several groups of people (single mothers, disabled, employable) in a single piece of legislation. Ontario was the only province to implement a two-tiered system of social assistance in which municipalities administered "short term" assistance while the province administered "long term" assistance. This two tier system is representative of Ontario's attempt to differentiate between the worthy and unworthy poor. Municipal social assistance which is administered locally within municipalities is done with a level of discretion that has not enabled provincial consistency in the application of legislation (Ontario Works or previous General Welfare Assistance). The accountability and authority for the administration of social assistance in Ontario rests with municipal governments and hence the "make-up" and reigning political approach over time has resulted in a diverse and complex system. Irving and Daenzer suggest that the implementation of the $C A P$ meant that social workers would have an increased role in intervening in the lives of the jobless. Despite the optimism that surrounded the 
implementation of $C A P$, the continued complexity and inconsistency of Ontario's social assistance system may have been unwelcoming to university educated social workers.

\section{Social Work as a Profession}

Since its inception and particularly in 1970s there has been debate within the literature as to whether social work is a profession. Nina Toren in Social Work: The Case of a Semi Profession (1972) questions whether social work is a profession. Toren uses the phrase "semi-profession" to capture the uniqueness of social work:

A semi-profession may lack a systematic theoretical knowledge base, and hence entail a shorter period of training for its members; it may not command a monopoly of control over its members, the criteria for recruitment, training, licensing, or performance; its code of ethics may be vague or inconsistent; and the professional association may be divided, inefficient, or powerless (Toren, 1972).

Toren's view is that social work lacks recognition by the clientele of social work and by the broader community (Toren, 1972). She does not believe that social workers have been able to demonstrate "exclusive competence" in the treatment of their clients and that the profession has much work to do in order to prove that with skills, efficiency and results it can do a better job than "any enthusiastic amateur" (Toren, 1972, pg.42). Contrary to Torens' view Maria O'Neil McMahon in her essay "Responding to the Call" (1992) suggests that social work is indeed a profession and one that has all the characteristics necessary to be identified as a profession. These characteristics include: values, knowledge, method, purpose and sanction (McMahon in Reid and Popple, eds, 1992). The profession of social work has attracted a greater ratio of women to men in the field and increasingly those recruited into the field of social work were from lower social strata which may deter those with uppward mobility aspirations from pursuing social work as a career (Toren, 1972, pg.56). 
Porter Lee has suggested that as the profession of social work developed, social work based inspiration declined. Lee believes that a rise of professionalism in social work negatively shifted its emphasis from "cause" to "function" (Jennissen \& Lundy, 2010). The focus on "function" versus "cause" is important to consider in examining the profession of social work in the administration of social assistance. Social workers who may already be challenged to defend their choice of career as a true profession may be even less likely to work in the field of social assistance which is often plagued by stigma.

Robert Stephens in The Discipline of Social Work: A Critique (1968) prefaces his work by acknowledging Social Work's early roots in offering aid to others, yet highlights that despite this history it has still not fully emerged as a profession (Stephens, 1968). Stephen identifies four features that must be demonstrated by Social Work or any other discipline in order to qualify as a profession and these include: the service is distinct from any other discipline, the service is based on a unique scientific process and goal, specific knowledge and preparation are required of its practitioners and that no other profession can offer the service as effectively (Stephens, pg.17). It is the last two features that would appear to present the challenge when considered in the context of the field of social assistance. Specifically, if social assistance is for the most part delivered by laypersons not possessing social work education and has been done so for an extended period of time, does this demonstrate that social work is not a profession or that the work of social assistance is not in realm of professional social work? I am cautious to not assume such ridged conclusions and beliefs, but to recognize that there are additional questions to be 
asked and explored such as "could social assistance be delivered more effectively if done by trained social workers"? I believe that this question underlies the work of this thesis but it remains an elusive and hypothetical consideration given that there is no time in history that social assistance in Ontario was staffed exclusively by university educated social workers.

Stephens is critical in his work of the National Association of social workers in the USA for being ignorant or irresponsible in permitting non social work educated people to align with the profession. Stephens believes that other professions that were firmly established in advance of social work had learned these valuable lessons and that social work should have been wise to the attempts of untrained and unqualified social workers to use the profession to their own ends (Stephens, 1968).

Stephens believes that social workers need to be courageous and carve out the definition of the profession of social work. He suggests that the seedling that was planted in defining the profession and that was nurtured during the early part of the century needs to continue. Stephens states: "At this historic time Social Work can no longer refuse to face a definition of itself in the vain hope that the need for it will disappear magically (Stephens, pg.27)". He recommends two essential responsibilities on the part of social workers that would assist in it gaining professional status. The first is with respect to the use of titles and the need for social workers to not use titles that reflect affiliation to other disciplines and second that social workers not use descriptive terms that are associated with other professions. The use of titles and terminology from other professions (i.e. 
psychiatric social work, medical social workers) may reflect the immaturity of the profession and possibly the inferiority complex of its members.

The work of social assistance typically does not align itself with any of the other professional disciplines and hence it is essential to consider this reality in understanding the involvement of social workers in social assistance. If the profession has indeed sought in part to legitimize itself through attachment to other professions, it becomes clear that the field of social assistance would not have been attractive, because social assistance has not historically aligned itself with any other profession. From this perspective, one wonders whether the work of social assistance is questioned as being one of the "true" domains of social work, in part due to its non-attachment to other disciplines. In addition, the early days of an inferiority complex on the part of the profession, it may have failed to acknowledge the opportunity and legitimacy that could have been achieved through the field of practice of social assistance.

Jennissen and Lundy (2010) in their book, One Hundred Years of Social Work: A History of the Profession in English Canada, 1900-2000, discuss the struggles of the social work profession in the 1970s and describe it as a "malaise" as cutbacks in social programs occurred and social workers saw their roles change from advocacy to monitoring and regulating (Jennissen and Lundy, 2010, pg.426). The 1970s were a time that social workers began to challenge the existing diagnostic and functional approaches to social work and many looked to systems theory as a better alternative. The gaps in systems 
theory, coupled with social program cuts resulted in growing concerns over justifying the profession of social work (Jennissen and Lundy, 2010, pg.427).

According to Irving and Daenzer the role of social work in the field of social assistance is one of meeting the goals of the organization first and second meeting the human needs and rights of the clients. The distinction between social work practice and other human service and social maintenance roles has been blurred. (Irving and Daenzer in Riches and Ternowetsky, eds, 1991, pg. 286). Reamer notes that data strongly suggests "a mounting neglect of public issues in favour of psychotherapeutic and casework services that for many workers may be more rewarding, respectable and lucrative" (Reamer in Reid \& Popple, eds., 1992). In addition, these areas of work would not require staff to perform policing functions that would be required in social assistance. Alan Keith-Lucas argues that social work has virtually deserted the poor in its quest for status and social acceptance. He suggests that movement to a more "community model" of social work, such as in Britain, would help in its consideration of the people served by social work as "constituents rather than clients" (Lucas in Reid and Popple, eds, 1992). The very nature of the work performed in the field of social assistance is being called into question by these authors. The field of practice itself appears to have acquired a stigma; a stigma that leads social workers to other areas of practice and a stigma that results in negative public perception. It is not only the issue of stigma for without the "cause" the "function" becomes a disciplining action without the caring and therefore contributing to the abandonment of identity. The field of social assistance by its very history, character and stigma may deter social workers from its employ. 
In Practise in a Public Welfare Setting (1981), Robert Teare discusses the setting of public assistance and warns that: "in the not too distant future, it is likely that social work education will be called upon to validate its claim to this occupational turf. Given the apparent diversity in program content and the lack of unifying principles, this may prove to be difficult" (Teare, pg.103). Teare suggests that "there is a need for social work and public welfare to examine their relationship as neither can afford to view the other with disdain" (Teare, pg.104). In the first section of this paper it was noted that the government had taken actions to "push out" social workers and Teare suggests that in modern times the issue is about attracting social workers to the field. The $1930 \mathrm{~s}$ was a time when social workers were first confronted with massive unemployment and poverty and in the post war period they influenced the creation of the welfare state; now as Teare suggests, neither the field of practice nor the profession is fighting to stay connected. It is that specific relationship between the profession of social work and work within social assistance that this thesis seeks to explore.

In 1980 and 1983 writer Norman Wyers published two separate articles in the American journal Social Work entitled "Whatever Happened to the Income Maintenance Line Worker?" and "Income Maintenance and Social Work: A Broken Tie". In both of these articles Wyers passionately makes the case for the profession of social work to not exclude the role of income maintenance worker from the boundaries of the profession. Wyers sets the context of his writing on the decision in 1967 by the Department of Health, Education and Welfare in the USA to separate the tasks of providing financial support to clients from the provision of broader social services. He attributes this 
decision partly to the advocacy efforts of the social work profession. In 1973 the National Association of Social Workers (NASW) published a classification system of social workers and it excluded the role of the welfare / income maintenance worker. Wyers believes that this omission only further de-professionalized the role of the welfare worker and suggests that such exclusion and inattention by theorists, researchers, and the profession of social work has relegated it to a second class status (Wyers, 1980, pg.261).

In 1979 Wyers completed a study in the USA and found that only three percent of the positions available in welfare offices were held by individuals with BSWs. In addition, the study revealed a general unavailability of training and education in schools of social work for working in the welfare field. In this 1983 article, Wyers suggests that BSW programs should take action to link themselves more closely with the public welfare offices and provide students with the skills necessary in public welfare work. The literature review earlier in this document cited the opinions of several authors who felt that social work has a moral purpose or possibly a moral obligation to assist those in poverty. In both articles, Wyers comments on social work's lack of involvement with the poor and its weak presence in the delivery of public welfare (Wyers, 1983, pg.264).

Wickenden and Bell (1961) agree that the image and reality of welfare services is that "social workers are influenced by community attitudes and tend to seek positions which are favorably perceived by their friends and families, avoiding those settings which are in disfavor" (Wickenden \& Bell, pg.108). They suggest that the community as a whole has yet to secure an adequate vision of the potential in the public welfare services for reversing the tide and social disorganization. Similarily, Dave Howe in his book Social 
Workers and Their Practice in Welfare Bureaucracies (1986) suggests that the field of practice that is chosen by social workers is perceived to directly reflect a certain kind of image. Howe suggests that the occupation of social work has always been sensitive about its image (Howe, 1986, pg.30). He discusses differentiation and stratification that exists in social work and comments that "the clean end of the job is the work associated with lowly stigmatized, potentially productive and aesthetically pleasing category of children and their families" (Howe, 1986, pg. 31). Howe believes that it is risky for the profession of social work to abandon what may be regarded as "dirty work" to achieve social buoyancy as in "doing so they also expose the myth of a service ideal and reveal some of the qualities needed in the political progress of an occupation" (Howe, pg.32). When Howe refers to "dirty work" it is assumed that he is referring to social work with individuals that may not be aesthetically pleasing, who may not be productive and who battle ongoing stigma, a group that could be seen to be that of the social assistance recipient. Similar to Howe, Howard Bushbinder also uses the word "dirty" and offers a structural perspective on the role of a social assistance worker in the following quote:

The social service worker stands at the interface, at the wicket in the welfare office, and faces the victim. The nature of the service is oppressive, in that it rationalizes the process of victimization. The rules and regulations provide a framework for defining the service and controlling the client. This is an onerous task for the worker who comes to the job believing in such concepts as client self-determination. In fact, the worker is a "dirty worker". (Bushinder in Moscovitch and Dover, 1981, pg. 365)

Thus the suggestion is that it is not only the nature of work that may not be desirable to some social workers but also, and at least equally significant, is the reality and the perception of the clientele by society. The work of social assistance would indeed lack attractiveness to social workers based on upon Howe's perspective; a view supported in the literature by McMahon. 
McMahon writes that traditionally social workers were identified with altruism, social justice and public welfare", but over time they have moved away from working with the poor to working with more affluent populations. McMahon expresses strongly in her article the belief that social workers have a responsibility to the poor:

Because of the continued needs of the poor for equal opportunity, improved social conditions, and social justice, and because of the unique, documented commitment of the profession, there is strong reason for social workers to accept their ethical responsibility and respond to the call to serve the poor today. Seeing their career as a calling helps social workers find diverse and relevant ways to demonstrate their purpose... (McMahon in Reid \& Popple, eds, pg.174)

McMahon notes the important role that the education in BSW and MSW programs has in promoting and encouraging, teaching and modeling for students to better understand their professional responsibility to the poor. In considering McMahon's comments there is the question as to whether social work graduates would concur with this viewpoint. What should the prerequisites be for entry into social work education and how does one measure potential altruism? The term responsibility is a strong word and not generally a consideration for young graduates who are actively seeking social work employment. If a social worker views the field of social assistance as not requiring her/ his skills and abilities as a social worker and if the field does not acknowledge (through recruitment, practice or salary schedules) social work attributes, why should graduates feel a responsibility? Not unlike graduates of other areas, social workers want to work in a field that values their educational accomplishments, recognizes such attainment through appropriate remuneration and assigns work to commensurate with their skills. This discussion highlights the various factors that have in the past and continue to influence the role of social workers in the administration of social assistance. A number of authors 
on this topic have used terminology such as: obligation, moral purpose and a "calling", to refer to work of social workers that serve the poor.

In Careers in Social Work (1998), Leon Ginsberg discusses the function of "eligibility determination" which is a significant part of the role of staff within the field of social assistance. Ginsberg notes that while agencies may prefer to hire BSW/ MSW graduates, the job in fact may not require a social work degree and many in this role may not have social work education. Ginsberg suggests that the role of eligibility determination may not enable a close connection between worker and client: "however there is nothing quite so helpful to people who are in financial need than helping them obtain money for food, clothing, and shelter. Some people think that eligibility workers are the most important people-helpers in the human services" (Ginsberg, 1998, pg.113). This thesis has been prepared with a personal bias that supports Ginsberg's acknowledgement that eligibility determination (similarly likened to the role of a social assistance worker) is critical and important human service work, work that belongs in the domain of the profession of social work. Understanding and acknowledging the reasons why few social workers work in the field of social assistance is not the same as drawing the conclusion that such work does not require social work professionals. There is also the reality that through successive conservative government strategies that the "social" has been taken out of "social work" and therefore perhaps the profession needs to focus its attention on putting it back in. 
Graham Riches paper "Welfare Reform and Social Work Practice" (1989) examines the role of social work in social assistance in Saskatchewan. Riches points to three main reasons for the withdrawal of social workers from the field of social assistance in Saskatchewan. These include 1) the work is practical and thus only requires a clerical function 2) social workers are too costly and 3) social workers can be too critical of welfare and raise too many questions about policies and regulations. All of these arguments are equally applicable to the social service system in Ontario.

Riches concludes his paper with a message that is hopeful for all social workers who have worked or will work in social assistance:

To the extent that social workers can still remain committed to respecting those who come to them for help and ensure that the needs and rights of these people are met, that policies and regulations that deny a person's value and humanity are resisted, and that colleagues and the public are informed of the issues confronting clients and practice, the task of social work is being accomplished. (Riches in Riches \& Ternowetsky, eds, 1991, pg.122)

Frederic Reamer in a paper titled "Social Work and the Public Good: Calling or Career" (Reamer in Reid \& Popple Eds, 1992) states that many social workers are no longer interested in pursing the broader ideals of justice and public welfare, but rather move forward with their career in social work with the goals of security, job status and high incomes. Reamer believes that the tension between "case" and "cause" has been an important factor in the evolution of the profession. Philip Popple states: "social work is a profession with a conservative social function but a liberal moral purpose, and so will always be characterized by a dynamic tension between the two" (Popple in Reid \& Popple, eds, pg.9). In the conclusion to his article "Social Work and the Public Good" Reamer suggests that both social work professionals and society need to demonstrate 
ideological commitment to welfare and a willingness to allocate the resources necessary.

Reamer offers the following comment to social workers:

A calling without professionalization is bumbling, ineffective and even dangerous. A profession without a calling, however, has no taps of moral and humane rootage to keep motivation alive, to keep human sensitivities and sensibilities alert, and to nourish a proper sense of self-fulfillment. Nor does a professional without a calling easily envision the larger ends and purposes of human good that our individual efforts can serve. (Reamer in Reid \& Popple, 1992, pg.30)

Max Siporin demonstrates a bit of nostalgia when he states: "Social Work as a profession needs to regain its moral vision and idealism and even the moral passion that the old-time social workers had" (Siporin in Reid and Popple, eds, pg.87). Not only have these authors attempted to establish a moral code and ethical obligation for the profession of social work, they also have not questioned but rather made the assumption that social work does adequately encompass work with those in poverty. Reamer and Siporin suggest that social work was at one time a profession that represented a strong moral character; a profession that acted in response to ethical obligations. These authors allude to the notion that this is no longer the case.

The Canadian Association of Social Workers (CASW) in its paper "The Impacts of Working Conditions on Social Workers and Their Practice" state that there is not only decreased funding for social service programs but also "less societal support for the provision of help to others" (CASW, pg.3). The CASW references the trend towards interdisciplinary teams which can challenge the identity of social workers as the occupational boundaries may become fuzzy. It suggests that such role conflict can lead to job related tension, anxiety and dissatisfaction. This is an important point and is likely one of the many factors that has influenced social workers in their noticeable absence in the field of social assistance. If the numbers of social workers that work in social 
assistance is low, then it is reasonable to assume that these workers have limited opportunities to liaise and interact with fellow social workers. Social workers who are isolated from similarly educated peers do not have the opportunity to retain and maintain a sense of connectedness to the profession. Stephenson highlights one of the issues related to management: social workers are not supervised by social workers which can lead to isolation within the discipline of social work and can result in social workers "not providing services to their full range of potential and skill" (Stephenson in CASW, pg.12).

This same point is echoed by Gail MacDougall as she discusses the reality that many social workers may feel professional isolation and suggests that "in the absence of someone who shares the same values and perspective of analysis of client situations, the need to explain continuously the nature of one's work is tiring and demeaning in some work situations" (MacDougall, pg.2). In summary, the work environment, staff supervision and identity within the workplace are important factors that may negatively influence social work staff retention in an environment such as social assistance.

In support of the above point, authors, Morales and Bradford note that income maintenance was once the primary discipline of social workers, yet in their work they identify that few social workers now report employment in this area. (Morales and Bradford, 1998, pg.108). The study "In Critical Demand" (2000) sets out to develop a profile of those employed in social work including the emerging trends, human resource realities and a forecast for the future. The study is thorough and comprehensive but one 
of its limitations is with respect to classification. It relies significantly on the National Occupational Code (NOC) system used by Human Resources and Development Canada and the study includes five different NOC codes, none of which are exclusive to university-educated social workers. The Sector Study, as it is often referred to, presents valuable insight into professional identity: it suggests that the profession of social work needs to put a great deal of effort into determining what social work is. The following is a quote in the study by the Prairies Association:

The future of the profession is to some extent based on its definition of itself, and making sure the public understands this. The whole idea of who we are and how we are identified is a crucial question for the profession across the country. We're not sure, and we're not good at communicating what we do. If we can't do that, we're at risk of others moving into our sphere of practice. (HRDC, pg. 87)

Toren (1972) suggests that some social workers feel that achieving a high level professionalization may result in a loss of basic humanitarian values and lessen its involvement in social reform (Toren, 1972, pg.43). Toren quotes Nathan Cohen: "social work without service would be lame, but without values would be blind" (Cohen in Toren, pg.43). Toren alludes to the fact that in its quest to achieve professional status, social work may have left behind some areas of practice including social assistance (Toren, 1972, pg.43).

Jennissen and Lundy (2010) who have written extensively on the history of social work in Canada, also identify the ongoing tension amongst social workers in relation to the pursuit for professionalization. These authors note that the social workers who are more engaged in social justice, teaching, unions and social reform are less interested in what has been coined as the "professionalization project". They discuss from their own work 
and that of other authors such as Cross, Wilding and Wagner, that two key characteristics of a profession are power and prestige; traits that are legitimized by government and that lend themselves to the perception of state alliance and traits that would clearly conflict with those working in such positions as noted above (Jennissen and Lundy, 2010, pp. 381-383).

David Macarov in "Certain Change: Social Work Practice in the Future" acknowledges the increasing role of social workers in supporting clients towards employment, a task that can be challenging when there are not enough jobs available or when there is a mismatch of jobs available. The current Ontario Works $(\mathrm{OW})$ program is considered an employment program and Macarov's uses the term "social worker" to identify those who support clients in seeking employment. Macarov challenges the social work community to shift from the traditional activities of training and motivating clients towards employment towards a new perspective of helping clients to "live fulfilling lives, despite their lack of jobs, to engage in satisfying activities, to not feel stigmatized, and to maintain positive self images" (Macorov, pg.11). Macarov acknowledges that such a shift is significant for social workers but suggests that such a reorientation will be necessary in the future. I am conflicted by Marcarov's comments, for I believe it is important work of social workers to motivate and support clients towards their employment goals yet I would agree with Macarov that social workers also need to partake in the de-stigmatization of clients. The Ontario Works Program is prescriptive and too often staff work is directed at "counting the widgets" and less about meeting the holistic needs of the client. 
Louise Johnson (1998) in "Social Work Practice: A Generalist Approach" argues that social workers who work within public sector fields of practice are subjected to a greater level of control by the public and aside from having less autonomy than other social workers, they also have more responsibilities to various interests (Johnson, 1998, pg.19). In the field of municipally-delivered social assistance, workers are responsible and accountable to multiple interests as Johnson suggests and include immediate supervisors, clients, community partner agencies, respective ministries and councils (upper and lower tier).

Similarily, Ginsberg (1998) suggests that public employees as opposed to nongovernmental agencies are subjected to greater criticism "and often without justification" (Ginsberg, pg. 115). This level of criticism and scrutiny, she argues, is in part because public employees are paid by everyone's taxes and that a "thicker skin" may be necessary for those social workers that choose to work in government agencies, of which social assistance is one example. Over time there has been a divide between government social workers and non-government social workers with the former receiving greater benefits, pay and job security and the perception that they have been co-opted by the state. This discussion may seem rather redundant and irrelevant because so few social workers may work in municipal social assistance, but I believe the discussion may highlight other factors to explain their absence. That factor is the perception of being co-opted by the state and being subjected to unjustified criticism as Ginsberg has noted. 
Gail MacDougall (2008) examines the influences and stresses on social workers in the new world in her article "Social Work Practice: Another Look" (2008). MacDougall believes that for some social workers, their workplace may challenge their basic social work ethics. MacDougall's following comment offers insight into why social workers might leave the employ of social assistance:

Placed in ethically compromising and challenging situations, often without support, many social workers attempt to reconcile their professional values with system values that are driven by the dominant political and economic agendas. Unable to effect change and unwilling to compromise on their values, a number of individuals likely change jobs or leave the profession altogether, without fanfare and with a sense of failure and anger. (MacDougall, 2008, pg.4)

Personal and professional ethics are particularly important for social workers and the nature of the work in social assistance challenges such ethics. Social Assistance staff must not only "manage" the client of social assistance but also balance and negotiate through their work in the context of legislation, provincial politics, economic realities, community pressures and municipal councils.

No discussion or literature review on the interconnectedness of social work and the field of social assistance would be complete with out citing the work of Ben Carniol. As a part time BSW student, while also working as a welfare worker, I was assigned to read the original edition of Carniol's Challenging Social Services. Every chapter of the book resonated with personal experience and the critique offered by Carniol legitimized the feelings of frustration that I was experiencing, but more importantly it forced me to a level of introspection that positively changed how I began to undertake my work. In Carniol's $5^{\text {th }}$ Edition, it is suggested that workers in social assistance may feel demoralized..."after all their training, social workers discover that while their social 
services do provide some hope to clients, at best they can barely scratch the surface of the problem" (Carniol, 2005, pg.82). This point affirms the importance of social worker involvement in the complex field of social assistance.

The literature review that has been presented here serves to ground the early beginnings of social assistance within the profession of social work, however these origins have not stood the test of time. Both the profession of social work and the field of social assistance have evolved considerably over the past sixty years, an evolution that has brought into question if such a relationship still exists and whether it should exist. These questions will be explored throughout this thesis with the goal of understanding where the profession of social work has been, where it is now and where it can go in the future with respect to the field of municipal social assistance in Ontario. 


\section{Chapter Four: Theoretical Perspective}

The theoretical framework for this thesis is political economic theory. This approach recognizes both the political and economic context in the development of social policies and the evolution of social work. A structural perspective grounded in political economic theory is appropriate for this study because social assistance by its nature is a program of limited and restricted resources and the programs are determined in large part by the prevailing political ideological climate of the day as manifested in the government. Howlett and Ramesh (1992) note that all modern societies rely on two key institutions for making decisions. The first of these is the state which is found in the realm of politics and the second is the market which belongs to the realm of the economy; the study of these two institutions is central to "political economy" (Howlett and Ramesh, 1992). The structure of the policies that govern social assistance have developed within a private market economy, a system that is particularly harsh for those who are not attached to the labour market. And, as this thesis demonstrates, downturns in the economy and trends toward more conservative political and ideological stances over the past several decades have appeared to increase the alienation of social work from social assistance.

Political economy is a theory that looks at social relations that evolve between people in the process of production, distribution and the consumption of material benefits. Canada has in the past and continues to operate as a capitalist society that is based in a private market economy with circumscribed government intervention. That is, there is the assumption that the private market is the most appropriate, effective and efficient way to distribute goods and services in society. The state in a modern neo-liberal society such as 
Canada, becomes involved in regulating only when the market is perceived to have failed to do the job. Power and influence are critical to this understanding. Those members of society who hold the most power are typically those who have the most wealth. Those with money and power will in turn have influence and control over such aspects as norms, beliefs, values and social institutions (Naiman, 1997, pg.72). Hence, those that find themselves living in poverty lack not only money but also power and influence. In a society driven by the private market, the interests of the ruling elite are typically dominant. This system becomes self perpetuating by its very nature which results in the maintenance of the underclass (lowest socioeconomic strata). Part of this substrata of society; that is, the working poor or the unemployed, play an important role in maintaining the existing power imbalance. They serve to act as reserve labour to be called on when and if required. Members of society who are not engaged in active productive labour remain outside of the mainstream of society.

Adam Smith wrote one of the first books on political economy, entitled The Wealth of Nations (1776). Howlett and Ramesh revisit Smith's thesis that every individual in society is motivated by self interest and "led by an invisible hand to promote an end which has no part of his intention" (Adam Smith in Howlett and Ramesh, pg.27). Smith became well known for his economic beliefs in not intervening with natural market forces because that would interfere and discourage individual enterprise and result in diminished economic well-being (Howlett and Ramesh, pg.27). Another influential political economic theorist that has had a significant influence upon the ideology of political economy is John Maynard Keynes. While Keynes was a supporter of the private market, 
he believed that there were situations wherein the state had to intervene in order to stimulate the economy. He maintained that the market could not always regulate itself and that an active state was necessary. This was a strong divergence from Smith's "invisible hand" and Keynesian economics became the economic base of the post-war welfare state in Europe and North America. Modern Keynesian-welfare economists believe that the operation of the market is a superior method to state intervention in distributing economic resources, but they also agree and concede that there are specific circumstances in which the state may be more efficient (Howlett and Ramesh, pg.36). Post-Keynesian thinking presumes that it is possible to predict and plan for market trends, but yet the market can be very unpredictable and proactive planning is not always possible. A political economy perspective places the responsibility for the creation and perpetuation of inequality and poverty on the shoulders of the private market and the political mechanisms that assist in maintaining this socio-economic structure.

Mulvale (2001), Haddow (1993) and Rice and Prince (2000) discuss the Keynesian welfare state and suggest that Canadians benefited from the Keynesian welfare state between 1940-1970 by having a modest level of economic security. Rice and Prince (2000) discuss the change in thinking that began in the late 1930s and how social policy and economics became viewed a being intricately linked. The goals of social policy and the goals of economic development were viewed as complimentary for as one had positive outcomes, the other would as well. The following quote by Rice and Prince highlights the Keynesian thinking of the time:

By encouraging consumer demand through public expenditures, the government could promote full employment - a goal of economic policy. The government could sustain economic growth by fuelling the economy, and yet, if prices 
became inflationary, it could withdraw expenditures and thereby cut back on economic stimulation. Politically this happy marriage of the welfare function and the economic management function decreased the hostility towards the introduction of large-scale social programs". (Rice, 2000, pg.57)

Keynes viewed the issue of mass unemployment as not a private issue, but rather a public concern that was to be remedied through social policy. Rice and Prince (2000) identify two time periods that they believe were key in the formation of the Canadian welfare state with the first was from 1937-1945 and the second period from the late 1960s to the early 1970s. Mulvale (2001) and Rice and Prince (2000) believe that the Keynesian welfare state has been be slowly dismantled since 1970 and political parties that had traditionally safeguarded Keynesian economic policies (i.e. NDP) adopted a more business friendly tone and abandoned their traditional practice of intervening in the economy in the best interests of social equality (Mulvale, 2001, pg.15). The welfare state came under scrutiny in the mid-1970s with increasing taxation, inflation and a growing number of Canadians were becoming dependent upon the welfare system, a time period often referred to as the "crisis of the welfare state". Rice and Prince (2000) identify that this crisis spanned the period of 1975 to the late 1980 s.

Gosta Esping-Andersen (1990) has categorized welfare state regimes into three categories; Liberal, Conservative and Social Democratic. He identifies Canada as being part of the liberal welfare state because of its pro-business political parties and that it is dominated by market logic. The liberal welfare state according to Esping-Andersen narrowly targets the most socially disadvantaged, it embodies little solidarity and is more prone to attacks by hostile political interests (Esping-Andersen in Haddow, 1993, pp.1314). The welfare state is at its weakest point during times of economic recession, and in 
the history of Ontario hostile political attacks upon those in poverty have never been more evident than in the Harris Conservative government campaign of 1995.

Naiman (1997) defines capitalism as an "economic system in which all production is subordinated to the imperatives of the market: accumulation, competition and profit maximization" (Naiman, 1997, pg. 89). Those living in poverty lack the ability to "save" or accumulate money or accumulate wealth thus making it impossible to rise out of poverty. This discussion is relevant to the topic of social assistance by understanding Canada's history of keeping "people down". Social assistance rates have never reflected the actual costs of basic subsistence for people in poverty. Such rates are economically and politically motivated and set low with the intent of forcing people into production. The concept of "less eligibility" has remained a central tenet in social assistance within Canada since the Elizabethan poor laws and it implies that the public assistance provided must not exceed that of the lowest paid wage earner. This concept still prevails in the current day Ontario Works program as reflected by low rates which are intended to act as incentives and / or force the economic motivation to produce and earn.

Deservedness for social assistance benefits is directly linked to people's ability to demonstrate their motivation and desire to be productive. However, there are exceptions as the social assistance system has created varying categories of deservedness at different points in time with exceptions being made for example to single mothers of young children and those with identified long term disabilities. The implementation of the Ontario Disability Support Program (ODSP) in 2000 signaled the end of "deservedness" 
for single mothers as their cases were transferred to the Ontario Works Program. Those with disabilities remained and continued to be served through the $O D S P$ program instead of the former Family Benefits Allowance (FBA) program. Those individuals in receipt of $O D S P$ received (then and now) a marginally higher rate of financial benefit and less restrictive asset limits than their counterparts in the $O W$ program. The economic logic of "less eligibility" is that a minimum amount is expended to support those in poverty and this low amount will motivate people back into the work force and thus serve the interests of the ruling elite. This ideology runs counter to the actual conditions of the impoverished who often cannot find jobs that will support them, or who have other circumstances in their lives that make it difficult or impossible to work in regular employment. The primacy of the private market in society basically means that individuals are expected to compete on the market for their own welfare. For those who cannot compete, this reality can be devastating.

While the welfare state developed policies that provided some measure of support for those in need, these policies have always played a contradictory role. In addition to providing some measure of benefit, these policies also serve to exert control over individuals and families. Rice and Prince (2000) believe that social policies are used by government as instruments to shape the way communities are organized and how people interact with each other. They suggest that there is a move away from social policies as measures of support and a trend towards the "greater use of rules in managing social policies" (Rice and Prince, 2000, pg.161). Margaret Biggs as cited in Rice and Prince (2000) speaks specifically to the welfare programs that "have rules that control 
entitlement, regulate the flow of benefits, create conditions for the withdrawal of support, and establish power and dependency relationships" (Biggs in Rice and Prince, 2000, pg.164). An example of this is the election of the Conservative government in Ontario in 1995 at which time the rules for social assistance were expanded and actions taken to ensure that "working" looked more attractive than social assistance.

Michael Katz provides the following quote to illustrate what he sees as competing goals for social workers working in the field of social assistance:

Welfare-never will be satisfactory. It cannot escape the contradictions between its goals of deterrence, compassion, discipline and control....or resolve the tension between entitlements and the market. (Katz in Struthers, pg. 157)

Burton Gummer (1997) speaks of the impacts upon agencies and the poor as our governments become more conservative. Gummer contends that growing conservative ideology supports the view that government is "intrinsically bad" and therefore agencies such as social assistance face what he describes as "double jeopardy". Gummer explains; "this new conservative ideology is not only anti-government, it is also virulently antiwelfare and anti-client which means that these organizations are also the victims of welfare-bashing" (Gummer, 1997, pg.351).

What has driven social assistance policy in Canada? All policy is about choice and balance and most often, but not always, in a capitalist society, the balance is in favour of the ruling elite of private profiteers. However, power is a relative concept and there are times when the working class has more or less power than other times. The relative balance of power between the classes is dependent on several things such as: dominant ideology, economic conditions, international conditions (i.e. wars), level of class 
consciousness in society, existence of working class parties, level of community participation, extent of trade unionism, types of political parties in existence, political party in power. Sylvia Bashevkin suggests that the in the late 1990s the language that was used by politicians and the media in regards to social assistance was moralistic, hostile and overall perceived as "poor bashing; it was language that "diverted attention from the human costs of spending cuts"(Bashevkin, 2002, pg.117). This fits with the ideology that supports cutbacks to social welfare because the vilification of the poor makes these actions more palatable and even necessary.

Graham Riches in "Feeding Canada's Poor" suggests that in the 1980s the rise of food banks was a sign of neoconservatism that signified the transfer of responsibility back to the voluntary and charitable sectors of society (Riches, 1989, pg. 135). By abdicating its role to alleviate poverty, the state forces the voluntary and non-government sectors to address social welfare issues. Bob Mullaly in The New Structural Social Work, $\left(3^{\text {rd }}\right.$ Edition) concurs with Riches but more directly places the blame upon the Canadian economic and political system. Mullaly suggests that Canada seems to be reverting to the very same situation that resulted in the creation of the welfare state in the first place (Mullaly, 2007, pg.17).

John Stapleton, an expert in the historical evolution of social assistance, has written specifically about the influence of politics and the market economy and how it has shaped our views about people on social assistance. He suggests that societal views towards the impoverished have become more negative. The economic upswings and downturns that 
the Canadian economy has undergone since the Great Depression have been significant and the pattern demonstrates that during periods of economic recession, policies and approach are generally conservative. The value of looking back at history is that it will not only help us understand and provide an analysis of what has worked and what has failed, but also to knowledgeably inform us as to the possibilities of the future. All economic recessions are unique, both in the precipitating factors and the duration. How the Federal government has responded to the different recessions has varied and Stapleton suggests that in dealing with the most recent recession of 2008 , the response has been reserved and meager. Stapleton (2010) references this as the "recession spook" in which politicians have not risen to the occasion to enhance social programs in the way they ought to during a recession to support the most vulnerable. Rice and Prince (2000) argue that in recent years we have not just cut back on social services but rather we have fundamentally shifted our views and patterns for addressing welfare. What is needed is not just to tinker with existing policies but rather it is about changing the whole system.

The dismantling of the welfare state continued with the introduction of the social contract in 1993 and in 1994 the implementation of a welfare fraud investigation initiative. In 1995 the election of Mike Harris resulted in political retrenchment of assistance to the most vulnerable and a conservative ideology that has permeated the social assistance system for almost two decades. Stapleton suggests that the recession of the 1990 s and the political response to it has "spooked" the politicians of today and that Ontario may never again return to its past recession strategies of enhancing programs during difficult times. The following is a quote by John Stapleton: 
So how we choose to fight poverty is just as important as the question of how much to spend. If poverty were attacked in the right ways, the savings from reducing it could be substantial... if poverty has a associated cost, then the reduction of poverty should generate an economic return (Stapleton, 2008).

Stapleton (2010) examines the five periods of recession in Canada since 1929 (1929 $1934,1957-1958,1973-1975,1981-1983,1991-1994)$ and while all were different and unique in their own way, there is evidence of Keynesian thinking in terms of government response in which social programs were enhanced to counteract the impacts of economic recessions. Increasingly the state was pressured to involve itself in social welfare issues, but not because it was benevolent but rather because of several political and economic factors. Some of the factors that got the state initially involved were the horrors of the great depression for while municipalities were going bankrupt, there was a great deal of pressure from the unemployed. This resulted in modest changes from the provincial and federal governments in the 1930s and 1940s. The war pulled the economy out of the depression and a different ideology began to emerge. Canadians had been traumatized by the war and wanted a state that promoted peace and advancements for the wellbeing of its citizens. During the war, the federal government assumed a great deal of power and thus when the war ended Canadians had become accustomed to the federal government playing a strong role. This strong federal involvement though was during a time of prosperity when changes were easier to make.

The welfare state began to shrink in the mid 1970s with claw backs to social programs. A more serious dismantling began during the $1980 \mathrm{~s}$ and 90 s, predominantly under Conservative leadership both federally and provincially (i.e. Harris, Klein, Mulroney). 
An eroding welfare state sends a strong message to the clients of social assistance programs and also to those working within the social assistance programs. Working in social assistance during this time would be tough and if you were a university educated social worker, I would suspect it would be even more challenging. Social workers who are educated and trained to help clients overcome poverty and its affects, would be directed to work within a system whose prevalent ideology is to provide band-aid solutions for those who are viewed to be at blame for their economic reality. Social workers who work in this arena and who are not co-opted by the state, see immediately that the problem is a lack of money and opportunities for poor people. Solving this problem is a huge issue and would require a restructuring of the whole system, rethinking our views on "work", and rethinking our perspectives on citizenry. It would require a revised view on the obligations of governments and societies to care for its most vulnerable members. In light of this, how does a university educated social worker whose training is based on understanding and assisting the underprivileged come to rationalize his/ her participation in such a system?

Working in social assistance is a difficult job, and the future does not appear bright. In many respects it is easier for social workers to focus their energies on something that can be positively changed through education (i.e. multiculturalism, anti-racist strategies). Social assistance hits at the root and heart of the problem of a system driven by a private market economy. That is, it is not designed to assist those who are not able to help themselves. This is particularly problematic when the Keynesian welfare state is eroded and there are no longer measures in place to attend to those who become victims of the 
vicissitudes of life. In this environment, where does the social worker interested in working with the poor stand? This conundrum may be another reason that many social workers opt to not work in the field of social assistance, a field of work that faces the very raw realities of the struggles of those living in poverty.

The maintenance of an underclass in a capitalist society has also served to create a conflict for social workers. The distribution of university educated social workers has not been targeted for the field of social assistance and nor has the consumption of social work knowledge been intended for the poor. A society that does not value those living in poverty and blames them for their lack of resources creates somewhat of a "mirror effect" for the social work profession. That is, in the same manner in which the state and society have generally abandoned the poor, so too have social workers unloaded the poor from their identity. Social work has distanced itself from the underclass; this is a reflection of what is happening in the broader context of the state and the capitalist society that characterizes Canada.

Ian Gough in The Political Economy of the Welfare State, notes that the welfare state is a contradictory phenomenon in which there are both positive and negative attributes and to disregard either one, as most theorists do, does not enable a balanced view. Gough proposes that the modern welfare state is unique and that it is a contradiction because it provides some measure of benefit to people but also it controls people. Moreover does the welfare state have the potential to sustain itself? The welfare state is a creature of a capitalist society, and as such it is prone to the vagaries of the market. It cannot be 
trusted to provide for the impoverished at precisely the time that the most help is required - during periods of recession.

Jim Ife as cited in Mullaly, discusses the profession of social work and how the changes in the economic, political and social environment may contradict the values of the profession. Ife notes that social work services are not valued within neoconservative ideology and social workers may in turn be labeled negatively with no recognition or respect for the values and ethics that they represent. Ife suggests that social services have grown to value more generic business based skills and staff in social services are not required to have social work backgrounds. Ife believes that this has had several significant results including: non social workers assuming managerial roles in social services, social workers identifying themselves by titles such as manager or casemanager as opposed to their profession, loss of autonomy for social workers and a growing belief that social problems can be solved by technical means.

Specific to this thesis, Ife uses the example of social assistance workers and believes that the competency movement in which formal education is de-valued and competencies valued, that de-professionalization is occurring in such occupations. If Ontario social assistance programs do not seek social workers for its employ and do not place value on social work skills and formal education, then this may reflect a field that has deprofessionalized social work. Other writers in this field concur; for example Fabricant, Burghardt, Dominelli, Fisher and Karger have also labeled this trend as the "proletarianization of social work" and the "deskilling" of social work which results in 
traditional social work functions being performed by unskilled staff. Mullaly notes that neoconservative policies that are passed on to social workers to implement result in contradiction to the profession's beliefs and values. (Mullaly, 2007)

According to Margaret Little the Ontario anti-poverty activists also felt that their influence was diminishing in the 1990s; Little states:

Activitists attribute this loss of political clout to a number of factors. Clearly, the political climate had changed dramatically with the economic recession. Middle-class citizens began to view themselves as taxpayers and the poor as a drain on the public purse. The poor themselves, to some extent, accepted this ideology and they, too, began differentiate between the worthy and unworthy recipients. (Little, pg. 158)

Irving and Daenzer discuss how many social workers in social assistance were preoccupied with the symptoms of economic dysfunction and family stress and fell short of "defining joblessness as economic abuse meted out by the state, and seeing family dysfunction as the effect of that abuse" (Irving and Daenzer in Riches and Ternowetsky, eds, 1991, pg.282). The authors suggest that the lack of recognition of the political economic forces is in part evidence that the profession lacked strong identity.

Understanding and acknowledging the role that both politics and economics play in the maintenance of the welfare state is central to understanding and bringing context to the relationship between social work and the administration of social assistance. The Elizabethan Poor Laws of 1601 established the early notions of deserving and undeserving poor and our political and economic realities have kept this notion alive and well in the modern day welfare policies. Capitalism necessitates that market forces prevail and therefore only productive members of society are valued. The welfare state in capitalism is mildly sympathetic to non producing citizens who are deemed disabled or 
have "legitimate" (worthy) reasons for minimal productivity. The private market typically does not strive to help the poorest and most disadvantaged of our society, but will rather support the most advantaged. The development and modifications to the Canadian welfare state are a direct reflection of both politics and economics at varying points in history. Political economic theory is useful for understanding the history of our welfare state and will serve as the framework upon which this thesis is undertaken. 


\section{Chapter Five: The Early Years of Social Assistance (1920-1944)}

The research question posed in this thesis requires a thorough exploration of the profession of social work, the field of social assistance and most specifically the points at which both have intersected over time. In the early stages of the development of this thesis, the research question had been envisioned as the task of "exploring the relationship" between the field and the profession, but with research and interviews completed it is clear that the term "relationship" is an exaggeration and the term "intersections" is more appropriate. The following five chapters will review the important intersections of the field of practice of social assistance and the profession of social work.

\section{Friendly Visiting and Charity}

Municipal delivery of social assistance in Ontario can be traced back to 1793 when Lieutenant Governor Simcoe failed to implement British Poor Law. This resulted in services to the poor being developed haphazardly and sporadically by the churches and charities at the local community level rather than by each municipality, as dictated by Poor Law. This set the stage for social assistance delivery for centuries to come (Stapleton, pg.7). Social Work as we know it today developed in the early years of the 1900 s and was born out of the tradition of charity. Early social workers were referred to as "friendly visitors" and many were seen to be doing the work of the church. The churches' roles in assisting those in poverty was significant in the early 1900s at which time the role of government was undetermined in such issues and the formation of the welfare state was not even on the horizon. It was not until the 1920s that the title of 
Social Worker came to be, with credit to some of the early social work pioneers (i.e. Mary Richmond, Simon Patten, Charlotte Whitton). Mary Richmond described "friendly visiting" as "having an intimate and continuous knowledge of and sympathy with a poor family's joys, sorrows, opinions, feelings and entire outlook on life" (Richmond, pg.180).

In the 1920 s the provision of social assistance was most often referred to as charity and while larger cities may have provided some assistance to the poor it was mainly the churches that provided and organized relief to those in poverty. The Charitable Organization Society (COS), which was founded by Mary Richmond, carved out a place for the profession of social work in the provision of casework services and friendly visiting for the poor in society (Jennissen and Lundy, 2010). These early beginnings helped to both establish a footing by which the provision of charity (later known as social assistance) was a task of a social worker and that the position and title of social worker had legitimacy through its provision of charity. Mary Richmond in "Friendly Visiting Among the Poor" highlights the challenge and the pressure that was placed upon "friendly visitors" as they were forced to give both alms and friendship until such roles were later assumed by trained workers (Richmond, pg. XV). This challenge that Richmond refers to is important in that this dual function of providing both financial relief and social support to the poor is one of the many factors that has influenced the relationship between social assistance and the profession of social work both in the 1920 s and onwards to 2010 . The early years of providing assistance to the poor appeared to have served an important and mutually reciprocal role for both the field of social assistance and the profession of social work. The profession provided much needed work with the poor through which it began to achieve legitimacy as a profession. 
In 1930 Prime Minister MacKenzie King denounced any responsibility of the federal government to financially support relief for those in poverty and affirmed this to be in the realm of provincial responsibility. Eighty years later in June 2009 the Federal Government once again thwarts the recommendation that it develop a national poverty reduction strategy and furthermore lends its support to provincially developed poverty reduction strategies. Author John Stapleton notes that in 2009 the federal government controls, administers and funds close to $85 \%$ of the income security programs in Canada and thus:

To cede social policy and governance respecting poverty to sub-national governments with no reasonable prospect of capacity or success - is either an act of cruelty or fantasy - and most likely both. (Stapleton, 2009, pg.6)

John Stapleton in his article "Municipal Social Services" (2010) stresses that there needs to be consideration of the different "thinking" that permeated society back to this time period. It is only with this understanding and lens that context can be given to the events of the time. The first is with respect to how the state viewed children, which was paternalistic. The state viewed lone / widowed parents as raising the Country's children and society did not speak of "parents affording their children" (Stapleton, 2010, pg.1). The view was that the state was the father and cash relief was paid through Mothers Allowance to its employees (mothers) to raise its children. This thinking changed at the end of World War II when the idea of the state as the "parent" evolved to instead embrace its role in promoting the growth of markets and the economy. The second difference in thinking of the 1930s is with respect to nutrition and disease for as the science of disease 
management, vitamins and proper nutrition grew it left behind the former eugenics movement.

\section{The Stock Market Crash and the Great Depression}

The date of October 29, 1929 is a significant one. Known as Black Tuesday, it represents the day of the stock market crash. While the crash occurred in the United States, its impact was equally devastating in Canada and its effect reverberated around most of the world. In general the 1920s was a time of great optimism and when wise investors had great prosperity but the market was not able to sustain the high price levels indefinitely and in over the period of one week (October 1929) the market lost a total of $\$ 30$ billion. The impact of the stock market crash was significant and showed itself through the loss of jobs, homes, savings and property. In addition its effects were reflected in a rise in the number of suicides, deaths from starvation, disease and the collapse of some industries. While there is some debate as to whether the stock market crash was the culprit of the Depression, there is little debate that it was indeed a significant factor. Additional contributors to the Great Depression included a drop in consumer spending at the time as well as a devastating drought in the Canadian prairies.

In the fall of 1929 Canada began to see the onset of a depression and by the winter months of 1930 , the incidence of unemployment and poverty was severe. In Ontario it was the municipalities that had the responsibility to address such needs, but with limited resources and entrenched adherence to the principles of "less eligibility" and "deservedness" not all responded and not all could respond. Ontario's response to the unemployed and the needy was inconsistent at best. Irving and Daenzer note that it was 
estimated that only 500 trained social workers existed in all of Canada, many who were engaged in private practice (Irving \& Daenzer, pg.272). Charolotte Whitton and Harry Cassidy both believed that social workers should have the responsibility of providing relief and case management services to those in need. Whitton and Cassidy differed considerably in their overall beliefs on approaches and methods of serving the poor, but such is a topic for a separate thesis. Cassidy believed that the skilful approach of trained social workers was essential in helping the unemployed. Whitton in the 1930s was concerned by the number of untrained social workers that came to work in relief offices and cautioned that Canadian social work would become engulfed and lose itself in the administration of relief. Whitton, like Cassidy believed in the value of having trained social workers administering and controlling the issuance of social assistance in Canada (Irving \& Daenzer, pg.276).

In The Limits of Affluence: Welfare in Ontario, 1920-1970, James Struthers examines the history of social assistance in Ontario and the role of social workers in it. The early history (1920s and forward) of social work lacked standards and guidelines for the determination of basic eligibility for public funds. In fact, the province of Ontario first became involved in the field of social assistance with an attempt to limit and control its dissemination. While social workers were directly involved in providing direct relief, it was not easy and they often found themselves battling for recognition.

In 1929 a Royal Commission on Public Welfare was appointed and in response to its recommendations, a provincial Department of Public Welfare was established in 1930. Struthers cites the depression as a time in which the fiscal crisis inhibited any serious 
welfare reform and it was a time in which debate erupted on the subject of "human need, social obligation and the imperatives of a market economy" (Struthers, pg.78). James Struthers believes that many of these debates were not resolved in the 1930 s and it that it was not until the 1960s that poverty was once again in the forefront that they were addressed (Struthers, 1994).

A survey and report titled "Unemployment and Relief in Ontario 1929-1932" was published by Harry Cassidy in 1933. Cassidy had been charged to evaluate the system of relief in Ontario and through his learning and experiences he made strong statements regarding the role of social workers in the provision of relief in Ontario. The vast numbers of unemployed and impoverished families made the provision of relief very challenging in the early 1930s and Cassidy noted that the task of distributing relief left minimal time to deal with other matters. Cassidy acknowledged that for social workers, the issuance of relief must be done "in conjunction with measures to make the family independent" (Cassidy, pg.198) yet Cassidy's report cites that only two to three Ontario municipalities reflected this point of view. Similar to Mary Richmond, Cassidy highlighted the struggle and conflict that existed in providing both financial relief and social support to those in poverty, a scenario that has been described as the dual purpose in the delivery of social assistance.

In the early 1930 s, a number of cities in Ontario prosecuted individuals for public welfare fraud and the local media reported high rates of fraud. Despite such reports, Cassidy stressed that many municipalities and their staff believed that relief was being 
administered fairly and staff believed that even more people were entitled to relief that were not even accessing it. Nonetheless, the negative media coverage and emphasis upon inefficient administration of public relief served to cast much doubt and skepticism on the provision of public relief. In his report, Cassidy notes that the quality of administration in relief offices was not high and mainly due to a lack of trained staff. He specifically referred to trained social workers and identifies that of the municipalities studied only four had trained social workers in charge of issuing relief. He further noted that the Mayors and councilors did not believe that specialized training or knowledge was required for the task of issuing public relief.

Also during this timeframe, Prime Minister Bennett commissioned a study on unemployment relief which was led by Charlotte Whitton. In the final report of 1932, Whitton suggested that $40 \%$ of those receiving public relief were not entitled to it, a conclusion that served to legitimize the federal government's lack of response to the impacts of the depression and its unemployed citizens (Jennissen and Lundy, 2010, pg.70). Cassidy believed that the issuance of public relief was the task of trained social workers. He stressed that the issuance of material relief necessitated the worker to also provide "courteous treatment, sympathetic consideration of personal problems... and a general readiness to deal with each individual case on its merits" (Cassidy, 1933, pg.202). Cassidy noted that several Ontario Municipalities had come to realize this as many had begun to hire and appoint trained social workers in public assistance departments in the early 1930s (Cassidy, 1933). 
In 1931, the four million dollars that had been allocated for provincial -municipal relief projects was exhausted, but the province refused to pay any more. Municipalities were left on their own to manage the vast need and poverty that surrounded them. In the early years of the depression the provincial and federal governments debated as to "who should pay for what" and thus neither rose to provide the financial support that was so desperately needed. Municipalities had nothing more than their property tax base upon which to draw and while the province allowed them to borrow funds this only delayed the inevitable reality that they could not support the vast need. Many municipalities ended up in a state of bankruptcy.

In 1932, Premier Henry struck the Advisory Committee on Direct Relief which was led by Wallace Campbell and from this came "the first real attempt to convert the provision of goods into cash equivalents and to standardize welfare policy and practice at the provincial level" (Stapleton, 2009, pg. 6). The standardized rates of assistance became known as the "Campbell rates". In 1932 each community in Ontario had a Public Welfare Board that was comprised of appointees who were charged with ensuring that municipalities did not issue any welfare funds to its citizens above the Campbell rates. The issuance of direct cash relief was introduced by the Campbell report but it was not realized until 1935 in part due to the fiscal crisis facing most Ontario municipalities. The Minister of Public Welfare, David Croll promoted the idea of "cash relief" and used the Campbell rates as the beginning to standardize welfare rates in the province of Ontario. 
The introduction of "cash relief" was not easy with even charities and social workers questioning the notion and while some municipalities used the Campbell rates, most still used their voucher systems to issue non-cash relief. Stapleton notes that prior to the 1930s municipalities had already developed services that they funded, administered and controlled:

They set their own welfare rates in defiance of the Campbell rates set by the province, they spent relief grants how they saw fit, ignored provincial inspectors, thumbed their noses at various reports, staged strikes, disobeyed directives and generally carried on as they had for the previous 130 years. In other words, at the local level, they ran the show. (Stapleton, 2009, pg.7)

Stapleton cites that $16 \%$ of Ontario's population received direct cash relief in 1935 and even more received other forms of non-cash relief (Stapleton, 2010, pg.3). In 1935 at the height of the depression, Premier Hepburn often referred to welfare recipients as "idlers" and did little to provide adequate financial support to the municipalities to deal with the crisis. In 1938 it was realized that there was significant inconsistency in the rates of social assistance across the province. The province announced in 1939 that it would cap the welfare rates at "Campbell +25 " meaning that the amount payable could not exceed the standard Campbell rate (as per Campbell rate chart) plus 25\%. Municipalities across Ontario varied in what they had been able to pay for welfare rates: some may have been issuing Campbell +5 while a handful of wealthier municipalities such as Toronto had been issuing Campbell +39 . Those municipalities that had been issuing welfare amounts above Campbell +25 were caught in a situation of having to standardize which involved welfare rate decreases which met with much opposition. The following quote by Stapleton highlights the contradictions inherent in the Campbell Report: 
The Campbell report is much more than a standardization of welfare rates: it is a Reflection of the times themselves... on one hand, the report dispassionately reduces basic human need into a dollars and cents valuation. On the other hand the report captures the tremendous social and political upheaval of Canadian society as it struggled to recognize and admit that the causes of poverty are complex... Campbell wrestled with the extent to which the market forces had failed Canadians. (Stapleton, 2009, pg.11)

By 1935 the issuance of public relief had peaked in Ontario and Premier Hepburn at this time announced some policy changes in an effort to reduce the numbers receiving assistance. While the cutbacks were met with strong mass protest by many groups/ agencies/ churches across the province, social workers were not visible in the protest (Jennissen and Lundy, 2010). In the City of Ottawa in 1936 a decision was made to relieve 40 female social workers of their jobs and in their place put fewer male bureaucrats to administer social assistance (Struthers, pg.96). This reorganization at the City of Ottawa resulted in protest and in particular the CASW publicly criticized the media for the negative slant put onto the profession of social work and most specifically it expressed its concern over the allegation "that a relief department which permits the practice of social work principles is inefficient and not economical" (Jennissen and Lundy, 2010).

Although social policies and programs existed earlier than 1930 (i.e. provincial mothers allowances, workers compensation) it was not until the Depression of the 1930s and particularly the second World War that the Canadian state become more involved in supporting the unemployed and other segments of the population that were deemed in need. It was not until 1940 that the Employment and Insurance Act came to be. In 1938 the CASW made a presentation to the Federal Government in Ottawa and they "made a 
strong case for the importance of hiring qualified social workers within the expanding machinery of government" (Jennissen and Lundy, 2010, pg.130).

\section{The Struggle: Unemployment and Poverty}

The depression had resulted in overwhelming financial demand in the areas of health care, education and welfare all areas of provincial responsibility. The challenge was that it was the Federal Government that held most of the revenue gathering powers while the demands were upon the provinces to provide a variety of social services. This reality could not have been predicted at the time of confederation in 1867 . It was the depression of the 1930s that highlighted the inadequate provincial -federal division of responsibilities. In 1937 the Royal Commission on Dominion-Provincial Relations was established and chaired by Newton Rowell and later by Joseph Sirois. In addition to the fiscal responsibilities of the provincial and federal governments, the regional disparities across the country became an important topic of discussion.

The Commission acknowledged that there was national inequity in terms of accessing basic services and an inconsistency in the quality of those services. The Commission made several recommendations in its final report in 1940, but at the Federal -Provincial Conference in January 1941, the provinces were divided in their support for the recommendations. In particular, Ontario, British Columbia and Alberta rejected the report, while Quebec waivered and Saskatchewan, Manitoba and the Maritimes supported it. The lack of agreement amongst the provinces forced the report to be shelved, however some of its recommendations reappeared in later years. The one recommendation that did 
come to fruition was the transfer of the unemployment insurance program from the provinces to the Federal government (Belanger, 2001).

\section{The Role of Social Workers}

In 1926 the Canadian Association of Social Workers (CASW) was founded: the association still exists today and modern day social workers acknowledge and look to the CASW in defining ethics and pride of profession. In 1926 the CASW strived to promote professional standards of social work by encouraging training and bringing public recognition to the field of social work. The establishment of membership criteria proved challenging for the CASW. In 1926 the CASW had five classes of membership which were modified in 1930 to only include two classes of membership. The 1930 CASW membership requirements did allow for non-social work educated individuals to join the CASW provided they met the experience expectations. In 1930 such membership criteria may have been regarded as flexible and helpful in bringing on new members. But was there a price to be paid for this flexibility in member recruitment? Was it a cost that the profession is still paying for? The value of social work education and what it means to be a professional social worker can be compromised when the "door is opened too wide". In 1930 a survey of Service Standards was completed with 228 social workers and only 81 actually had a university course in social work, with the remainder having a nursing diploma, special basic training or no training at all (Jennissen \& Lundy, 2010). The survey results assist in demonstrating that the title of "Social Worker" was not restricted to those of social work education. If the title of "Social Worker" lacked integrity / and clear definition in 1930, has it changed from then until now in $2010 ?$ 
The mid to late 1930s was a time period in which social workers were trying to find their identity and to establish their niche within the professional world. This task proved challenging as there were multiple and competing viewpoints. There were people such as Harry Cassidy, Margaret Gould, Porter Lee, E. Urwick, Ethel Parker, Dorothea Jackson and Saul Alinsky that urged social workers and the profession to become active in such endeavours as advocacy, promotion of legislative changes, social action and social reform. These leaders in the field of Social Work saw not only a role but a professional responsibility to do more than just "casework". However not all social workers of the 1930s agreed with such visions and hence the profession failed to carve out a clear and well understood identity. A divide existed between those social workers that focused on psychoanalytic concepts in casework and those that advocated for social action. There did not appear to be much middle ground on the meeting of these two distinct perspectives.

Organizing social workers was also challenging as many practicing social workers were not members of the CASW. Jennissen and Lundy conclude that near the end of the Depression, social workers were for the most part focused upon casework, the individual and on professionalism although the impact of the Depression had a serious politicizing effect on social workers. This time period necessitated that social workers and the CASW work together to not only advance the issues of human welfare nationally, provincially and municipally but also to support the rise of the profession of social work. 
Instead of these two goals being sought out, the goals were viewed as incompatible and thus only served to create tension within the profession (Jennissen and Lundy, 2010). 


\section{Chapter Six: Post-War Recomstruction (1945-1973)}

\section{The War and its Aftermath}

K. Grant Crawford made an address at the Ontario conference on Social Welfare on June 14, 1947. It is within this address that the views and struggles of Ontario municipalities in dealing with public welfare can be understood. Crawford discussed several points to explain the challenges of Ontario municipalities in the delivery of social assistance. First he noted that the election of municipal representatives by their local constituents makes it "reasonable to assume that the rate at which our municipalities extend their welfare activities is roughly indicative of the effective public opinion in those communities" (Crawford, pg.1). Crawford stressed that elected officials have a primary responsibility to those that elected them, not to those in need of assistance. In the address, Crawford believes that public relief should be issued by municipalities but that the financial burden of it should be borne by the provincial order of government.

Crawford acknowledges the perception of municipal councils as it relates to the field of social welfare as slow, unprogressive and "penny pinchers" and urges that that those involved in welfare work put an effort into understanding public bodies and to develop an "appreciation of the techniques of government and the psychology of councils" (Crawford, pg.5). In particular, the shortage of trained social workers is highlighted in the address and also the inefficiency of 897 municipal welfare units being involved in the administration of public relief. Crawford suggests in his address that 40-50 welfare units could be formed to more adequately and efficiently administer social assistance in Ontario, a vision that becomes a reality in Ontario, but not until 1998 which is further 
discussed in Chapter 8 of this thesis. His vision places emphasis upon efficient services being provided by highly skilled social workers that would comprise the staff of the welfare office. In 1947, Crawford notes that a key problem in attracting trained social workers is not only the limited supply but also the very low salaries being offered by municipalities.

Harry Cassidy and Charlotte Whitton are credited with promoting a vision of Ontario social assistance that reflected the values of social workers and that provided a prominent role for them. Harry Cassidy was commissioned by the Department of Public Welfare to examine relief giving in Ontario. In this report he was extremely critical of the cumbersome and ineffectiveness of social assistance in Ontario. Cassidy believed that the system of relief at that time in Ontario was being administered by "incompetents" that lacked social work training. The following is a quote by Cassidy:

By and large there has been no serious effort to recruit trained social workers for relief administration.....young social workers that remained after the reform movement found their conditions of work increasingly uncongenial, so that one by one they retired, baffled and discouraged. (Cassidy, 1945, pg.361)

However, Cassidy's views cannot be interpreted to be representative of all social workers or people involved in the field of social welfare, including equally influential pioneers as Charlotte Whitton and Leonard Marsh. While social workers were key to the formation of the welfare state, their varying roles were also part of the debate. The efforts taken to promote the profession of social work were every bit as laborious as the effort to advocate and support the interests of those living in poverty. 
Charlotte Whitton, who is one of Canada's renowned and contentious leaders in social welfare, made similar observations to those of Cassidy after administering a survey in 1944 commissioned by the Province's Welfare Administrator. In her survey results Whitton emphasized the need to put trained social work professionals in charge of the Ontario welfare system. She differed from Cassidy in her approach and supported such early practices as differentiating worthy and unworthy poor. However, both Whitton and Cassidy stood behind their solid belief that social assistance administration was the work of professional social workers. Whitton also recommended at this time that "all provincial and local welfare schemes should be merged into one general assistance program administered through a system of 49 welfare units" (Struthers, pg. 130). It is interesting that in 1998 the province of Ontario undertook a restructuring of social assistance and reduced the administration of social assistance to 47 municipalities (Consolidated Municipal Service Managers) as well as 2 northern areas known as District Social Services Administration Boards. While this restructuring in 1998 may not fully represent the comprehensive recommendations that Whitton made in 1944 and Crawford in 1947, it is glaringly coincidental that 54 years later the recommendation of 49 delivery agents (also known as Consolidated Municipal Services Managers - CMSM and District Social Services Administration Boards - DSSAB) is realized in the province of Ontario.

In 1944, Burne Wismer Heise a social work graduate from the University of Toronto, was appointed Deputy Minister for the Department of Public Welfare. Heise recommended, and began to move forward, on some of the issues previously promoted by Whitton and Cassidy including provincial cost sharing arrangements. What Heise had underestimated 
was the responses of Ontario municipalities who expressed objections to not only the cost of the approach but also the lack of control over welfare spending that would result. Rebuttals to social assistance re-organization were heard from many people including, Grant Crawford of the Ontario Municipal Association who criticized Cassidy by noting "that too often social workers lost sight of the fact that the primary responsibility of the elected representatives, is to those who they represent and not to the underprivileged or those in need of assistance" (Struthers, pg. 134). The Welfare Units Act underwent so many revisions by the time of its passage in 1948 that it no longer represented the vision of Heise, Cassidy and Whitton. Struthers notes that the Welfare Units Act became a political embarrassment as soon as it was passed as it was extremely vague and permissive. Heise's social work approach to welfare issues was in stark contrast to the perspectives of his Minister, Premier and municipal politicians. What is unfortunate in this situation is that a key opportunity was lost to better affect change for people in need. Furthermore the profession of social work and other social workers who followed afterward likely had greater challenges in actively participating and influencing the political sphere as a result of this lost opportunity.

Harry Cassidy in his book Public Health and Welfare Reorganization (1945), discusses how the welfare departments in some of the larger cities were well established yet the smaller towns and rural townships lacked any formal way to deal with the poor. In many of these small rural areas the provision of assistance (if any) was conducted by local officials who had several other responsibilities besides social assistance. One of the gaps within the guidelines at the time was that unemployed men were not eligible for basic 
assistance because it was felt that all men, particularly young healthy men should be able to find work. The longevity of this approach is considerable for when I began employment with social assistance in Leeds and Grenville (Ontario) in 1992 the local practice was that all single employable men who received social assistance were terminated in May of each year. It was explained that the municipal council believed that there was sufficient seasonal employment to ensure that young men could find some form of work and that allowing them to continue to receive benefits beyond May would contribute to dependency and reduce their motivation. As a social assistance worker there was a requirement to apply this rule until it ended in Leeds and Grenville in 1994. While general labour was in demand at the time, Cassidy felt that the policy should be amended to be prepared for a time when unemployment would rise. The lack of policy to deal with unemployed men is described by Cassidy as not being "socially defensible"

Author Alvin Finkel in Social Policy and Practice in Canada: A History (2006) describes the political economic dilemma from 1945 to 1980 . Finkel states that in the 1950 s there was a "widespread belief in the country that federal policies, as opposed to the operations of the capitalist system, were largely responsible for the concentration of capital in the country in the Golden Horeshoe region" (Finkel, pg.254). While economists challenged such thinking, it proved futile in a debate that was driven by emotion rather than practicality (Finkel, 2006). The St. Laurent government did introduce equalization grants in 1957 but such redistribution efforts were limited when wealthier provinces reacted with hostility towards this approach. 
The 1950 s represented a period of high unemployment and the Canadian Welfare Council (CWC) worked to convey the reality of Canada's poor through lobbying efforts and the preparation of various reports. Liberal Prime Minister St. Laurent took no action and deferred the issue to the provinces. The CWC planned to host a National Conference on unemployment to force the federal government to take notice. At the request of the Prime Minister, the CWC agreed to cancel the conference on the promise that the issues would be brought forward at a planned Federal- Provincial conference. This conference eventually led to the Unemployment Assistance Act in 1956 . The action taken by the CWC represents one of the most significant victories of the social work profession at the federal level (Struthers, pg 20). Finkel describes the impact of the new Unemployment Assistance Act as beneficial to many poor Canadians, but with the exception of Newfoundland, municipalities were left in charge of administering social assistance. In many situations the higher the costs of social assistance in municipalities, the tighter the eligibility criteria that were imposed. The result was that there were varying philosophical approaches across the country regarding the delivery of social assistance; this was also reflected in the varied social assistance policies (Finkel, 2006). In the late 1950s the CWC argued for a reconceptualization of social assistance which slowly came to be with the introduction of CAP in 1966.

In 1954 a conference for Direct Supervisors, Administrators and Branch Directors was held in Toronto. During the Conference the Minister of Public Welfare; W. A. Goodfellow advised those in attendance that they needed to keep a close eye on welfare relief and that they needed to be "objective and firm, but at the same time, seeing that 
people did not suffer" (Conference of District Supervisors, pg.2). At the same conference a report by D. Crittenden (personnel officer for the province) was made in regards to a recently implemented relief staff evaluation which was designed to evaluate both the knowledge and quality of work for field staff. Crittenden reported in the evaluation of the workers, that the worker - client relationship required the greatest skill. The results of the examination revealed that most field workers generally liked their clients and attempted to be helpful as much as possible. The examination results showed that most staff were able to positively handle their respective positions (Conference of District Supervisors, pg.18). It is interesting to reflect on this account and attempt to gain insight into those qualities that were sought after in the welfare field workers. In addition it is also interesting that the province undertook this evaluation of municipal social services staff and established the competencies to be evaluated. What is not clear from this transcript is the "buy-in" from the municipalities and the value that there may have been, given to the examination results by the municipalities. At the conference, Crittenden asks that supervisors take the examination results seriously, but notes that municipalities know their employees best and that the province is "content to leave the matter to your own sense of fairness and good judgment" (Conference of District Supervisors, pg.19). Not unlike today whereby the province continues to set the rules (directives and regulations and funding contracts) but yet the delivery which includes staffing is fully within the control and oversight of the municipality.

Similar to the 1950 s, the 1960 s represented a time in which many Canadians were living in poverty, yet there was reluctance by government to acknowledge this. The United 
States had declared a "war on poverty" in the 1960 s and the Pearson government in Canada echoed the same commitment. In 1961 the Economic Council of Canada (EEC) developed a formula to calculate what is commonly known today as "low income cut offs". This formula took into the consideration the cost of items, such as food, clothing, housing and miscellaneous expenses. In 1961 this formula calculation suggested that $27 \%$ of Canadians lived below the (LICO) (Finkel, 2006, pp.250-251). In 1967 Kenneth Carter released the Report of the Royal Commission on Taxation which confirmed that the Canadian tax system favoured the wealthy and that the poor were the group most negatively impacted. The report made numerous recommendations but many that were not acceptable to the corporate community and were put aside or significantly modified under the Trudeau administration (Finkel, 2006). The politics and the economics of the day led to the Federal government's reluctance to acknowledge in any significant way strategies to address the poverty at that time. David Croll led the Senate's appointed "Committee on Poverty" in the late 1960s. The final report suggested that in $1969,25 \%$ of Canadians were poor, despite recent economic growth and a growing number of twoincome households (Finkel, 2006, p.252). There were also regional disparities in which Finkel noted that the Atlantic provinces experienced a poverty rate of three times that of Ontario in the late 1960s (Finkel, 2006, pg.252).

\section{The Canada Assistance Plan \& Role of Federal Government}

Federal funding to support the welfare of Canadians first occurred in the form of conditional grants to the provinces after WWI and then were re-established in the $1930 \mathrm{~s}$ to assist the provinces with the demands placed upon them by the Great Depression. 
There was an ongoing rivalry between the Federal and Provincial governments and two commissions were formed to examine and propose recommendations to this tenuous relationship. They were the National Employment Commission (1938) and the Royal Commission on Dominion-Provincial Relations (1939). Both Commissions held that the federal government should have the responsibility for relief of the unemployed yet employable persons (Moscovitch, 1988). Hum cites two sources for the lack of commitment to social welfare on behalf of the higher levels of government: the social philosophy of the Confederation era and the legacy of the Elizabethan Poor Laws (Hum, 1983, pg.12). After 1941, the Federal Government ceased to provide conditional grants and the financial cost of relief were left to the municipalities (Moscovitch, 1988, p.1). The Canadian Welfare Council (CWC) campaigned for increased funding of welfare and helped to push the Federal government into negotiations with the provinces and soon after in 1956 the Unemployment Assistance Act was introduced (Moscovitch, 1988, pg.2). The CWC continued to advocate and released a report in 1958 entitled Social Security for Canada which called for the establishment of a new Public Assistance Act. In 1962 the National Council of Welfare (representatives included provincial deputy ministers, welfare agencies and schools of social work) urged federal cost sharing to include additional programs (Moscovitch, 1988, pg. 2).

The introduction of the Canada Assistance Plan (CAP) in 1966 represents a significant social policy change in the terms and conditions of the administration of social assistance. $C A P$ was introduced during a period of economic prosperity under the Federal Leadership of the Liberal government led by Prime Minister Pearson (see appendix D for further 
information on time periods and Federal and Provincial leaderhship). The goals of $C A P$ were to implement better and more comprehensive coverage for those in need of assistance including the working poor, to increase support for the unemployed and to consolidate assistance programs (Hum, 1983, pg.4). Irving and Daenzer view the CAP as giving social workers an increased role in their interventions in the lives of the jobless. The $C A P$ focused on social assistance as the most basic of anti-poverty programs (Hum, pg.14). The introduction of the $C A P$ brought acknowledgement by the Federal Government of the needs for it to support financially (in part) the costs of social programs. $C A P$ was instrumental is its commitment to cost share with the provinces the costs of social assistance, child welfare, homes for special care and other welfare services. The federal government believed that the $C A P$ would bring "order and consistency to the cluttered, and often disjointed, provincial public assistance systems (Hum, pg 14). CAP committed the federal government to pay half of any increase in provincial expenditure on welfare services; services whose main objective was the lessening, removal, or prevention of the causes and effects of poverty, child neglect, and dependence on public assistance (Hum, 1983, pg.70). CAP is significant in that it represents a time in history that through legislation the Federal government took on a portion of financial responsibility for its poorest citizens.

\section{The Role of Social Workers}

Social work in the 1940 s was a time to take stock. Over the years social workers had developed some knowledge of dealing with the impoverished and were familiar with severe poverty that had characterized the 1930s. This was a time when the profession of 
social work began to think about branching into more preventative and advocacy work. One example cited by Jennissen and Lundy (2010) was the Montreal Branch of the CASW which in 1939 set up a group on "Nutrition and Relief" with the goals of promoting relief rate increases in the face of cost of living increases. This period was also challenged with a severe shortage of qualified social workers and in an effort to ration the supply, the CASW attributed higher value to the work that social workers were doing with the war effort as opposed to work with such groups as the disabled and seniors (Jennissen and Lundy, 2010). There were four new schools of Social Work established in Canada in the 1940 s. The 1940 s was a time period that social work historians refer to as the "glory days". It appears to be a time that recognition and value for the work of social workers came to be, that social work education programs ( 8 in total) were on the rise and the CASW had government connections and influence. At this time the CASW grew to sixteen branches with an ever increasing influence on the social and economic development of the country (Jennissen and Lundy, 2010).

The 1940s was also a time that concern began to grow with respect to the working conditions and recognition of the value of social workers. Social workers were slow and reluctant to form or join organized unions and this was often out of their concern for the perceived conflict with their relationship to clients. Jennissen and Lundy (2010) suggest that this conflict was fostered from earlier days when charity work was done by unpaid staff and hence the concern that promoting professional status may be seen as competing for the resources that were already limited, for clients. Staff associations became the 
standard forum for social workers to advocate for better conditions and salaries (Jennissen and Lundy, 2010)

In 1943 the CWC and CASW prepared a memorandum regarding the supply and demand of social workers. The estimate at this time was that only one third of all jobs that required social workers were actually filled by staff with social work training (Jennissen and Lundy, 2010, p. 255). During a national conference in 1948 it was suggested that a national survey be undertaken with welfare agencies to better understand the supply and demand of social workers. The final report was released in 1954 by National Health and Welfare which concluded that there was "a serious shortage of qualified welfare staff across Canada" (Jennissen and Lundy, pg.329). In addition, this report highlighted that only $30 \%$ of the staff working in welfare were graduates of social work, yet the agencies indicated that their demand for social workers to occupy such positions (current or future) was between $78-86 \%$ (Jennissen and Lundy, 2010, p. 330).

The commissioner of Toronto's Welfare Department, H. S. Rupert made an effort to recruit social work graduates during the 1940s and 1950s, however his efforts were met with little success. It was assumed at the time that the working conditions and the poor salaries inhibited the interest of social work graduates. This in general resulted in staff working in the welfare department with little professional training, high turnover rates and chronic morale problems. Staff with professional social work education often felt demoralized and it came with the realization that there was little time to work intensively with clients. This suggests that salary alone was not the only deterrent as the nature of the 
work and perhaps the inability to do "social work" also impacted those in the field. Michael Katz highlights that there are contradictions (i.e. compassion, control, deterrence) in the work of social assistance and that resolving and accepting these may be too difficult for social workers. To further compound the availability of trained social workers, the schools of social work in the province saw enrollment decline in the 1950s.

Harry Cassidy led the creation of the National Committee of Canadian Schools of Social Work (NCCSSW) in 1945 in an attempt to assemble social work educators. This Committee worked hard to secure federal funding for social work programs and its other goals included providing a structure for the advancement of social work education in Canada, in part through the development of curriculum and teaching methodologies (Jennissen and Lundy, pg.327). Allan Irving and Particia Daenzer (1989) note that Cassidy not only believed that increased social assistance was needed but also large scale provision by social workers of:

... competent and sympathetic advise and assistance to the unemployed and their families regarding the many problems out there other than just those of a material nature which beset them. (Irving and Daenzer in Riches \& Ternowetsky, eds, 1991,pg. 275)

In 1953 the Toronto Branch of the CASW investigated the labour shortage of social workers and concluded that poor salary and benefits, low status of the profession, high education costs and ineffective recruitment for training were all contributors to the low supply (Jennissen and Lundy, pg.257). The notion that social assistance work was that of "charity work" was hard to shed and not only by government and the public but also by the social workers themselves. The lack of value placed on the profession of social work coupled with the lack of supply were key factors cited by the CASW Branch in Nova 
Scotia in the early 1950s as affecting the supply and demand concerns (Jennissen and Lundy, 2010).

Interview participant, Hugh Drouin (2009) believes that the profession of social work missed a key opportunity in the early 1940s to ensure that it carved out its place and role in the administration of social services in Ontario. This key opportunity is with respect to the education of social workers and how the delay in establishing Bachelor of Social Work (BSW) programs to meet social work demands resulted in hiring outside of the profession. Drouin notes that in the 1940s the Masters of Social Work (MSW) became the required degree, but there were not enough graduates to meet the demand. The suggestion by Drouin is that if social work had developed the BSW programs in a more timely fashion, it would have been able to meet the demand for staffing social assistance programs and thus begin to establish itself as the prerequisite of service delivery. Instead the delivery of social assistance by the numerous municipalities of Ontario at the time had few options but to hire outside of the social work profession.

It is important to remember at this juncture that the delivery of social assistance was the responsibility of municipalities in Ontario and hence they had full discretion to hire who they wanted and had sole discretion as to the desired qualifications of their employees. Stapleton notes that in the mid-1940s, municipalities viewed the establishment of social work standards as yet another attack on their administration of social services. According to Stapleton, the municipalities perception was that the province was: 
Stapleton describes this time period as being characterized by several debates that were not limited to administration and standards. The ongoing debate is described as being:

... deeply rooted in opposing political philosophies that pitted welfare state
economists against free market followers, universities, certifled professionals
and academics against tough-minded local politicians, the federal government
against the provinces, the left against the right and ironically the province
against itself. (Stapleton, $2010, \mathrm{pg} .9$ )

Despite that there was a wide variety of political economic forces at competing odds, many social assistance administrators believed that their work needed to be separated from the ongoing political debates of the varying orders of government. To this end they saw value in having some professional social workers working alongside them.

Administrators of social assistance in 1947 discussed the notion of forming a professional association and in 1949 the Ontario Welfare Offices Association (OWOA) was formed; its first conference was held in 1950 in which forty people attended. The association had the support and encouragement of then provincial welfare director: James Band (Stapleton, 2010, pg11). The OWAO was later renamed the Ontario Municipal Social Services Association (OMSSA). In my professional capacity I have been a member of OMSSA for the past eighteen years and can personally speak to the work that OMSSA does in providing professional development and policy advocacy in all social program areas that now rest with municipalities. When originally formed OMSSA was focused solely upon social assistance, but with provincial downloading of other social programs (i.e. social housing, child care) it has expanded its support to municipalities in these areas as well. OMSSA was in part financially supported by the provincial government up until 1995. 
The election of the conservative government in 1995 signaled the end to financial support and since that time OMSSA's self sufficiency has depended upon revenue from training and conferences held for its members. The mandate of OMSSA and their current goals / outcomes are:

To build our members' capacity to plan, manage and deliver quality human services in their communities. OMSSA's stated goals / outcomes include: Increased public acceptance of the importance of human services to healthy communities, more progressive public social policy and program design, increased member capacity to plan, manage and deliver integrated human services, higher calibre professionals delivering human services. (OMSSA Website, 2010)

What is not highlighted in the above statement is the significant role that OMSSA plays in offering training programs to municipalities for their staff. OMSSA plays a pro-active role in offering training to staff of social assistance.

In the 1950s schools of social work were vulnerable with some universities questioning whether social work education even belonged in the university. Public welfare case management was performed by both trained social workers and lay persons, both bearing the title of "social worker" (Irving \&Daenzer, pg.280). This concern from the 1950s is still as relevant today as it was then. Irving and Daenzer reference the 1950 s as a time when social workers began to expand the fields that they worked in and along with a decline in enrolment in the schools of social work and a decline in federal grants to social work academic programs, the profession was in the midst of an identity crisis. In 1957 an interim committee was struck with representatives from CASW, NCCSSW and CWC entitled "Canadian Committee on Social Work Education". The committee was struck for the purposes of facilitating communication between the schools of social work, the professional associations and employers. One of the sub-committees had the specific task 
of exploring the "study and development of purpose and program of education for persons entering the welfare field" (Jennissen and Lundy, pg. 332) including the possibility of establishing undergraduate social work programs. The 1950 s represented a time of severe shortage of trained social work personnel. The CWC highlighted its concern that in many agencies there was little differentiation between the professionally educated social worker and the lay person in the field and expressed concern that this threatened the delivery of competent services in communities, to the recruitment of potential social work students and also to the status of the profession. The CASW was concerned by the number of untrained welfare workers entering the field and the CASW decided to enhance its membership criteria but this decision was not supported by those members that felt the criteria should be broadened.

In 1963 at a CWC Conference there was a decision made that the CASW would advocate alongside provincial organizations and the $\mathrm{CWC}$ and Federal government to ensure minimal training for welfare workers. At the conference the following distinction between professional social workers and welfare workers was developed and approved and it consisted of the following three points:

1. In general terms, a professional social worker is one who works in situations in which the exercise of professional judgment is a primary characteristic of the service rendered, while a welfare worker is engaged in rending welfare services to people on the basis of defined criteria of service established in the programme in which he is employed. The precise interpretation of the distinction between welfare worker and professional social worker will depend on decisions made by responsible provincial associations of social workers.

2. Both types of service are important to the community and both types of workers are entitled to recognition and status.

3. Formal training is essential for any person who works with people in a welfare program. The content of such training differs from full professional education, but should be not less than 12 month' duration, part of which should be formal instruction and part field practice. This is essential to improve the quality of 
service to people in need and to assure the public that welfare personnel have received preparation of a certain standard for the performance of their tasks. (Jennissen and Lundy,2010, pg.338)

I believe that this moment in history is pivotal in understanding what can be argued as "second class status" that is afforded to "welfare work". The action of distinguishing a professional social worker from a welfare worker sends a strong message that the work of welfare is not that of social work. It is recognized that this move may have been in part driven by the severe shortage of social workers and the goal of ensuring that at least some educational / knowledge standards were established for the field of welfare, but did it go too far?

As a researcher of this topic and as a person who has worked as a social worker in this area for several years; I believe that the vision was short sighted and that it compromised the integrity of the profession, particularly those working in social assistance, and ultimately, those people who rely on social assistance. The influence of market forces in this decision is evident and once this decision was made it would have been difficult for the CASW to retreat, thus firmly establishing the second class status on social assistance workers. The CASW actions at this conference ultimately resulted in the CASW cutting out social assistance workers from any association with professionally trained social workers. This action set in motion even more challenges for "welfare workers" to identify themselves as social workers. Hence, I am proposing that the "status" (or lack thereof) of social workers in welfare is not a new phenomenon but that the CASW and social workers had a role in creating this divide. 
To further solidify this separation, the CASW proposed an examination for welfare workers and identified four main learning modules that would include: universal needs of people, dynamics of behaviour, welfare services and basis intervention skills (Jennissen and Lundy, pg.338). This limited concept of what welfare workers needed to know to perform their work would appear short sighted. Norman Wyers (1983) as cited in the literature review (Chapter 3) would certainly have challenged this simplified approach of the CASW. The reintroduction of BSW programs in the late 1960s did result in a significant increase in the number of social workers with a BSW or MSW. Also during this time a "social welfare worker" program was created at Ryerson Polytechnical Institute in Toronto and many anticipated that the introduction of this program which was shorter in duration of study and not at the university level; that it would lead to the establishment of second-class citizens within the profession (Jennissen and Lundy, 2010, pg.344).

In 1964 a consultation meeting was held between the CASW and the National Committee of Canadian Schools of Social Work (NCCSSW) at which time questions were asked of the CASW as to how they would be involved in the training of welfare workers in recognition that the CASW at that time had not allowed those trained with less than a BSW to become members. The CASW acknowledged their concern that there was an increasing number of untrained workers in the field of social welfare and yet also bearing the title of social worker and expressed their desire to improve the situation. Today, in Ontario the registering college for social workers is called the Ontario College of Social Workers and Social Service Workers (OCSWSSW), as its membership represents those 
who have completed college based social service worker programs in addition to those with BSW's or MSW's. The website for the OASWSSW offers the following definition for the respective professions:

Social work is a profession concerned with helping individuals, families, groups and communities to enhance their individual and collective well-being. It aims to help people develop their skills and their ability to use their own resources and those of the community to resolve problem.s (OCSWSSW, 2010)

Social service workers administer and implement a variety of social assistance programs and community services, and assist clients to deal with personal and social problems. (OCSWSSW, 2010)

As a social work professional, who also works in the field of social assistance I am dismayed and concerned about the descriptions of the OCSWSSW as cited above. The description for the social service worker specifically mentions "social assistance programs", but yet the description cited for social workers are competencies that that are also essential, in my opinion, when working with clients of social assistance. In my opinion these descriptions only serve to further convey that the work of social assistance is not in the purview of the social work profession, and that less educated professionals can suffice in such roles. If my interpretation is reasonable, then this is short sighted and the compromises that have been made along the way in this regard are ultimately to the detriment of social workers, the field of social assistance and the clients. 


\section{Chapter Seven: Social Assistamce in Ontario (1973-1995) \\ The Federal Provincial Social Security Review}

In January 1973 the federal government initiated a Social Security Review with the goal of improving the system of social security for Canadians. The first outcome of the review was the passage of the Family Allowances Act in December 1973. The first Family Allowances Act was passed in 1944, but the revised act of 1973 saw benefits increase from an average of $\$ 7.21$ per child to an average of $\$ 20$ per child and while considered taxable they would be adjusted annually with the consumer price index (Guest, 1987, pg.186). The Family Allowances Act was the first action taken as part of the review and from there the framework for the review was structured into five broad strategies and the first of these was the "community employment strategy".

This first strategy was implemented through a number of pilot projects across Canada with the goals of improving job skills and assisting those with struggles in remaining attached to the labour market (Guest, pg.187). In an interview, Dick Stewart, former Commissioner for Ottawa Social Services, discussed the implementation of these "work activity projects" and recalled that in Ontario pilots were set up in cities such as Ottawa, Kingston, Hamilton, Toronto and Windsor. He noted that the pilot projects were aimed at assisting the chronically unemployed and Stewart assisted in the co-ordination and development of the Ottawa project. Stewart noted that the project included training for life skills coaches, group work, and new innovative approaches to assisting clients with employment goals. Stewart believes that these projects forced municipalities to think differently. That is, to think differently with regard to its clients and the necessary 
supports that they required. Stewart described it as a "mindshift" in which the pilot projects introduced a fundamental concept which was: "these people need help and that there is a need to provide honest resources to help clients be better adjusted" (Stewart, 2009).

An additional strategy under the Social Security Review was the "income support and supplementation strategy". In The Emergence of Social Security in Canada, Dennis Guest notes that this particular strategy was very significant and warns that it should not be underestimated. The strategy involved a serious attempt to develop a national plan to supplement the incomes of the working poor (Guest, pg.190). The Federal government quickly realized that a goal of full employment was not possible, but did move forward in developing over a three year period a proposal for a two tier system. The first tier would be an income support program for those unable to work such as single mothers and people with disabilities and a second tier that would provide income supplementation to the working poor based on demonstrated need. Guest critiques this strategy as bringing a residual approach back to social assistance, an approach that had been set aside with the introduction of $C A P$ in 1966 . However, Guest notes that there were promising improvements to this two tier approach which included that: it would be inclusive of many working poor, through simpler eligibility criteria it would be less demeaning and would enable recipients to earn additional funds through employment (Guest, pg. 193).

A third strategy under the Social Security Review was the "social and employment services strategy". This strategy proposed services to those people who struggled in 
finding and holding employment which included social assistance recipients. The help proposed included counseling, rehabilitation, and child care to assist them in getting back to the work force. The provinces felt that the view of the federal government was too narrow and residual. After two years of discussions, review and negotiation there was agreement between the federal and provincial governments in 1976 to implement a new approach to the financing and development of social services in Canada (Guest, pg.194). While much work went into the Social Security review, the political and economic realities of the time prevented it from coming to fruition. The rising levels of unemployment, the inflationary pressures in 1974 and 1975, the introduction of wage and price controls and the Quebec election of the Parti Quebecois in 1976 all contributed to the plan falling off the rails. In an effort to salvage the recommendations, the federal government moved forward into discussions with the provinces.

The original recommendations and plans were diminished to the point of the federal government providing cost sharing to the provinces and its financial commitment was cut by two thirds to only $\$ 350$ million (Guest, 1987, pg.197). At a minimum the federal government wanted to introduce the Social Services Act, but in 1977 some of the provinces began to express their objections (Guest, 1987, pg.197). Thus, it never came to be, but this was a very significant time period in which the face of social services in Canada and the role of the federal government in supporting the poor was on the brink of defying history and setting the stage for the future...never to be realized. 


\section{Ontario: The 1970s}

McNorgan describes the late 1970s as a time that both administrative and political awareness grew in the province of Ontario in regards to General Welfare Assistance. In the early 1980s there was discussion of the Family Benefits program taking over GWA and this was very threatening to Municipalities. Family Benefits was a program that served single parents and disabled persons (often referred to as Mother's Allowance and Disability). The Family Benefits program was administered directly by the Ministry of Community and Social Services and was funded with $100 \%$ provincial funding. If $G W A$ was to be "taken over" by $F B A$ it would have meant the demise of all municipal social service departments and the end to municipal delivery and control of social assistance. McNorgan recalls the early $80 \mathrm{~s}$ as an era in which the approach of social assistance workers began to become less prescriptive and more oriented to "tell us what you need to succeed". The 1980s was also a time in which OMSSA was very active in policy development with many staff and a strong purpose to work closely with Ontario municipalities to support their delivery of GWA (McNorgan, 2009).

\section{The Liberal Years}

In 1985 Premier David Peterson was elected as the first Liberal Premier for Ontario since Harry Nixon in 1943 . The Liberal years were a time of introspection about social assistance...questioning social assistance and reviewing the social assistance system. Several reports were undertaken and released, all with the objective of identifying the necessary steps for overhauling the social assistance system in Ontario. One of these reports was National in scope and was undertaken by the National Council of Welfare in 
1987. The report titled Welfare in Canada: The Tangled Safety Net made numerous recommendations for improving Canada's social safety net. The recommendations included simplifying the complex rules of social assistance, modifying the approach to needs testing, increasing rates of assistance, modifying its approach to enforcement, developing consistent and fair processes for appeal to implementing communication strategies and sharing information with clients and the public about the system. All of the recommendations presented in the report were intended to be broadly applicable to all provinces, but Ontario along with Nova Scotia and Manitoba were singled out in regards to their two-tier welfare system. The report recommended that these three provinces move to a single provincial system of social assistance.

In July 1985, the Ontario government established the Social Assistance Review Committee comprised of twelve members with a mandate to establish the guiding principles of social assistance, to conduct an evaluation of whether the current programs met its objectives and to identify what changes are required to the social assistance system. The committee was struck as a result of a disturbing phenomenon in which social assistance caseloads were growing, while there was declining employment. There was also the perception that social welfare agencies were not well co-ordinated to help clients with multiple needs. The committee was comprised of twelve members appointed by the Ministry of Community and Social Services from all regions of the province, including some members that were former social assistance recipients. The committee released its final report Transitions in 1988; it contained 269 recommendations for how Ontario social assistance could be improved. The report described the social assistance system in 
Ontario as; antiquated, value laden, devoid of clear, logical and consistent rationale, stigmatizing, complex, inequitable, adversarial and overall a system that violates individual rights and principles of fairness (Report of the Social Assistance Review Committee, 1988).

One of the areas identified in the Transitions report that informs this thesis is the municipal delivery of social assistance in Ontario. The report suggests that the division of responsibilities between Ontario and its municipalities has resulted in great disparities in how the program is delivered and that the quality of delivery is affected by the preparation and education of those delivering social assistance. The report cites the province as having failed to provide the minimum standards to municipalities as it relates to caseload size and training requirements of staff (Social Assistance Review Committee, 1988).

In May 1992 an additional report was prepared and released titled Time for Action: Towards a New Social Assistance System for Ontario. This report outlined numerous directions that the new social assistance legislation needed to take. The report identified the need for legislation to set out in its regulations the various positions and functions of field staff to ensure clarity and consistency. It also urged the province to take a greater role in supervising and enforcing consistency and quality in the delivery of social assistance across Ontario (Time for Action, pg.131). 


\section{The Rae Days}

In furthering the work done of the Social Assistance Review Committee as presented in Transitions, an advisory group on new social assistance legislation was struck in 1990 . The committee presented its final report Back on Track in 1991. The final report was built upon the recommendations from Transitions. The report envisioned that actions would take place by the provincial government to set both caseload standards (i.e. maximum caseload sizes) as well as standards of service which would be achievable through the development of a human services and training strategy (Advisory Group on New Social Assistance Legislation, 1991). The report criticized the amount of resources that social assistance offices were putting into their intake areas, citing it as neglecting those already receiving assistance and who needed support to exit the system (Advisory Group on New Social Assistance Legislation, 1991). The Ontario Municipal Social Services Association (OMSSA) was quoted in the report and called upon the province to set the standards for service levels and service quality in its service contracts with municipalities. To date, such service contracts continue to capture only numerical targets and financial data with minimal qualitative measurement.

In an interview with me, Professor Moscovitch who led the team for the Back on Track report, commented that the recommendations that had been put forward in the Transitions Report were too risky for Rae to implement. To ensure that these measures were not adopted, Marion Boyd was moved out of the position of Minister of Community and Social Services and replaced by Tony Silipo. Marion Boyd was regarded by Moscovitch as being a tough-minded minister and as a former director of a women's shelter she was 
aware of the issues at a grass-roots level. Boyd was supportive of the initial recommendations and would have worked to having them implemented. This would have been too costly for the Premier since the Federal government had placed limits on its funding to social assistance for Ontario ( 1 of 3 of the wealthiest provinces in Canada at the time to have a funding limit imposed). The impact was heightened by rising social assistance caseloads in part due to the recession and cutbacks to Employment Insurance.

In addition, Prime Minister Chretien signed the Free Trade Agreement in 1988 with the USA and the provinces were under considerable pressure not to make business investment in Canada appear to be more favourable than those in the USA. Government subsidized programs were regarded as providing an unfair advantage to Canadians. Moreover, the NDP, of which Rae was the head was considered to be throwing money at the problems and to have taken any other approach would have cost too much money (Moscovitch, 2009). The Transitions report called for the province to consolidate its numerous districts, but smaller rural municipalities did not support this and the Association of Municipalities of Ontario (AMO) did not support this move either, so Rae did not move forward. The NDP was beset by many factors including an economic recession that was outside of their control, but enough to ensure that they would not retain power through the next provincial election in 1995. 
Summary of Influential Provincial Reports During the era (1985-1992)

Transitions: Report of the Social Assistance Review 1988

Committee

Back on Track: Report of the Advisory Group on New 1991

Social Assistance Legislation

Time for Action: Towards a New Social Assistance

1992 System for Ontario

\section{The Role of Social Workers}

Bob McNorgan, former Administrator of Social Services with the City of London, in particular notes that since he started working for the City of London in 1978 it was very clear that they did not hire social workers. When McNorgan first started working for the City it had just become a municipal requirement that staff have a grade thirteen education in order to be employed in social services. This was an increase from the previous requirement of a grade twelve diploma. The $G W A$ program was viewed by the municipality strictly as providing financial assistance and many of the staff that were hired in the 1970s were retired police officers and insurance investigators. The hiring of this personnel infers that the municipality was more concerned about rules, regulations and financial bottom lines than it was about the overall welfare of the people it was serving. The role of caseworkers was to direct clients, not to enable or empower them.

Case worker training, done on the job included little on working with people but rather focused on how to spot men's shoes at the front door of a single female client's home: how to identify vehicles in the driveway which could mean that there was an undeclared 
spouse, or a friend in the picture who might be providing some financial support to the client.

In the late 1970 s the City of London hired a social services commissioner Glen Howlett (MSW) who brought a social work approach to the business. McNorgan describes the late 70 s and early 80 s as a time within the City of London that changes started to happen. First there was the acknowledgement that what they were doing in social assistance was not working well because of the high recidivism rate. Second, some of the newer municipal politicians were women who seemed more determined to bring positive changes to the delivery of social assistance.

Moscovitch noted in the interview that many administrators in social assistance did not have education in social work and that often the preference was to hire clerical staff to perform the functions in social assistance. He cautions that the perception of social work also influenced the employment of social workers in social assistance. Moscovitch believes that up until the 1970s many believed that social work was about clinical practice and this was not perceived as useful in the context of social assistance. The relationship between social services and the social work profession was ambiguous as social work did not want to see themselves as part of the field of social assistance and welfare administrators not seeing social work as beneficial to their work. In some cases welfare administrators believed it was better to hire staff that could follow rules and be willing to work within the system rather than oppose it. Both Allan Moscovitch and Dick Stewart 
commented that social assistance was not seen as desirable work and was often considered the most undesirable form of social work. (Moscovitch, 2009, Stewart, 2009).

In the 1980s the city of London began to hire social workers but this was only for policy positions which were limited in numbers. Staff at the city of London were encouraged to go back to school but were specifically encouraged to enter into the Diploma of Public Administration program through the University of Western Ontario. In 1985 London decided to hire a manager for social assistance, but the human resources department was clear that is was not interested in a social worker as the more desirable qualifications were oriented towards business. McNorgan notes that the provincial discussions at the time were that social assistance needed to be restructured and that the province of Ontario wanted General Welfare Assistance (GWA) to be run more like a business. 


\section{Chapter Eight: Social Assistance - Moderm Day (1995 -2009) \\ The Commonsense Revolution}

The modest changes under both the Liberal Petersen government (late 80s) and the NDP Rae government (early 90s) would be long forgotten after the Mike Harris Conservatives came to power in 1995 . The previous term of the NDP government under the leadership of Bob Rae, came to a halt when only $20.6 \%$ of Ontarians voted for NDP in the 1995 election. In June 1995, the conservative government was elected as the premier of Ontario, receiving $44.8 \%$ of the vote (Ralph, 1997, pg.13). Harris's election campaign in early 1995 promised radical change in many areas of social policy and most profoundly in the area of social assistance. The election campaign highlighted what the Conservatives believed to be true and that was that social assistance system was characterized by rampant fraud, high rates of dependency and welfare rates that exceeded all other areas of Canada. Through their vote, Ontarians said they wanted a change. The Harris Conservative government moved quickly after the June election to implement an unprecedented number of changes. The election of the Conservatives became coined as the "Common Sense Revolution" reflecting the views of the public and the media in their perception of the enormity of the change that was required. Weinroch suggests the public's "hyped up response to crisis defiticism" produced the optimum conditions by which to justify the two key components of the Common Sense Revolution; authoritarianism and class prejudice (Weinroch, 1995).

The social assistance system in Ontario moved from the NDP era into the Conservative's Common Sense Revolution very quickly. Following the election of the Conservatives, 
the system braced itself for the impending changes. Within six months of the election, Harris cut social assistance rates (effective October 1,1995 ) by $21.6 \%$ and made numerous policy changes including the tightening of eligibility for youth, common law spousal situations and those in quit / fired employment situations. In addition, the welfare fraud hotline was established and the former JobsOntario program was cancelled (Dare, 1995).

During the 1990 s social work positions within the Ministry of Community and Social Services were frozen, yet the Ministry proceeded to announce the hiring of 250 investigators to review welfare case files (Little, 1998, pg. 160). It was a time when much attention was given to the notion that many welfare recipients were committing fraud. Politicians and media both exaggerated and misinterpreted the real numbers involved in fraudulent activity after the intensive review was completed. The reality was that fraud had not increased, but both the media and the politicians encouraged "welfare fraud hysteria" which consequently "incited hostility against the poor" (Little, pg 161). The practice of more strongly regulating welfare is consistent with a conservative era. Focusing on fraud, setting up "snitch lines" and turning people against each other is intended to erode the liberal base of social assistance. Convincing people that those on welfare are cheating the system is an effective means to receive public support for cutting back on these services. There is little in the way of questioning the ethics involved in this form of propaganda because it is widely supported by conservative elements in society. Nonetheless, its impact on the impoverished is both unfair and devastating. 
The period of the late to mid 90 s was a time when social assistance underwent more significant changes, changes that may have negatively influenced the role of social workers in the delivery of social assistance. One example of a significant change was the end of the Family Benefits Allowance (FBA). The FBA program was more commonly referred to as mother's allowance and in 1999 the Act governing $F B A$ was replaced with the Ontario Disability Support Program (ODSP). When ODSP was created all of the former mother's allowance cases were transferred to the Ontario Works Program and the only cases that remained with the province were long term disabled people. This transfer resulted in single mothers now having the requirement to seek employment or work towards the goal of full employment. I believe that this change in approach in 1999 marked the point at which the provincial government no longer believed that single mothers were members of the "deserving poor". The market economy had come to recognize the wage-earning value that single parents held. I believe that forcing them into $O W$ from the $F B A$ program, where they had previously received exemption from participating in the labour market, was harsh and in keeping with other conservative program changes implemented during the "commonsense revolution".

Implementing and enforcing the new policies of the conservative government in social assistance was challenging and presented for some, including myself, moral conflict. People working in social assistance suddenly had to take on more of a policing function than they had previously and for some social workers this was counter-intuitive to what they saw their work as being. The Harris government brought the implementation of new technology which meant that staff were now office-bound with applications having to be 
done at a computer terminal, thus signaling the end to home visits. Some staff in social assistance viewed this as restricting and less client centred. While implementing technology was intended to enhance the integrity and accountability of the social assistance system, for staff it presented only a new way to do business, not a better way of doing business.

In 1997 the Ontario Works Act replaced the former General Welfare Assistance Act. The new act and its accompanying regulations emphasized that it was now an "employment program" and that unlike the former general welfare assistance program; people would be receiving a "hand up" not a "hand out". Still in 2010, the Ontario Works program is referred to as an employment program, thereby through the "power of language" it skirts the reality that the program serves to meet the most basic human requirements of those most in need and living in social and financial poverty. Former UBC professor of Social Work, Graham Riches, acknowledges that social assistance has evolved to be more employment program focused;

Social Workers can no longer avoid the issue of unemployment. If our work is to help individuals, groups and communities respond to loss and change while bringing about beneficial social changes, then the issues of unemployment and labour-market marginality, whatever their political significance, have to be faced. If we are relatively uneducated about these problems, then we must start learning. If we believe we are already knowledgeable, then we must act. (Riches in Riches \& Ternowetsky, eds, 1991, pg. 300)

The impact and the speed of the Harris changes to social assistance appear to be unprecedented in Ontario. The journal articles, edited books and newspapers all portrayed the heavy hand of the new Conservative government. In general most literature condemns the Harris agenda and viewed it as a dismantling of the social safety net for Ontario's poorest citizens. One of the policy changes that received a great deal of 
attention was "workfare", the concept that social assistance recipients would be required to complete volunteer work in their communities in order to receive their social assistance benefits. The reaction to this particular policy change seemed to overshadow many of the others and in many communities across the province there were protests and lobbying of councils to take a stand against the impending changes. Many argued that workfare could not be implemented due to the provisions of the Canada Assistance Plan. That is, under the $C A P$, the provinces were prohibited from withholding benefits from anyone in needs of assistance (Morrisson, pg.72). The workfare program was a dramatic departure from this and it represented a clear ideological shift towards the notion of the deserving and non-deserving poor. With this policy change, the provision for social assistance was set back a century. Despite the strong protest against workfare, the program was implemented. Euphemistically called "community placement" the program served to pressure those on social assistance to work for welfare or to engage in a process of retraining.

Interview participant Bob McNorgan recalls the city of London's reaction to workfare and how a variety of city agencies filled the council chambers with their posters and placards to boycott the workfare program. McNorgan, along with London's Chief Administrative Officer, Commissioner and select council members visited the Minister of Community and Social Services, Janet Ecker to discuss their concerns about the Harris changes to social assistance. McNorgan and Dick Stewart both commented that not all of the changes brought about by Harris were negative but this was not clearly evident to those outside the field of social assistance. McNorgan felt that the new Ontario Works 
program brought in by the Harris government actually offered a "huge basket of opportunities" to clients that did not exist previously. Stewart highlights that Harris brought a different attitude towards social assistance and with this came the linking of social assistance and work. Ontario Works was introduced as an employment program with an emphasis on not just providing income support, but also employment supports which opened the door wider for staff and for clients to access assistance beyond just their basic needs.

The issue of "workfare" was controversial. While the conservatives had paved the way with legislative changes to facilitate the implementation of "workfare", how it was actually delivered and enforced was at the discretion of municipalities. Thus the delivery model in many municipalities did not necessarily resemble the "visions" held by early protesters.

\section{The End of the Canada Assistance Plan}

In April 1996 the Canada Assistance Plan (CAP) was replaced by the Canadian Health and Social Transfer (CHST). All conditions previously associated with CAP were dropped with the one exception that provinces could still not prohibit access to social assistance based on residency. The removal of conditions was viewed by some as a sign that the federal government was stepping away from any national commitment to the poor (Morrison, 1995). For Ontario, the effects had already started to be realized in 1991 when, along with Alberta and British Columbia, the 50/50 cost sharing arrangement was changed. The federal government implemented freezes to these three provinces and thus 
before $C A P$ officially ended, Ontario was already only receiving $\$ 0.29$ for every dollar from the federal government in 1994-95 (National Union of Public and General Employees, pg.17). The freeze imposed by the Federal Government in 1991 was hard felt as Canada was in the midst of the 1990 recession coupled with growing social assistance caseloads. The end of $C A P$ and the resulting loss of billions of dollars of federal support for social programs signaled the end of the Canadian social safety net. In 2004 the CHST was restructured to delineate the federal transfer costs for health from the costs of social assistance, social assistance and post secondary education. The transfer for these services is known as the Canada Social Transfer (CST) (Social Assistance Statistical Report, 2006).

\section{The Municipal Reorganization of Social Assistance}

The Local Services Realignment (LSR) initiative was announced in 1997 and it represented a significant change in municipal and provincial roles and responsibilities. The $L S R$ involved municipalities taking on greater financial and service responsibilities in the areas of emergency medical services, social community and health services and transportation and utilities, in exchange half of the costs of education were removed from the property tax base (LSR web resource, 2009). The goals of the $L S R$ were to provide greater accountability to the taxpayer, ensure the maintenance of critical standards, streamline service delivery, reduce duplication and capitalize on local expertise. The $L S R$ brought to municipalities the funding and delivery of social housing which prior to 1998 had been a provincial responsibility. The $L S R$ also resulted in the delivery of social assistance being consolidated from the former 196 municipalities to 47 Consolidated Social Services Managers (CMSM) and 2 District Social Services Administration Boards 
(DSSAB). The $L S R$ resulted in significant reorganization of smaller municipalities across the province. This prepared municipalities in recognition of acquired service and financial responsibilities for such programs as social housing and child care in addition to Ontario Works.

While the LSR did not include discussion of the role of social work, it was a very significant change in how social assistance was delivered and ultimately any change of this magnitude needs be considered in the context of the field and the staff within. The LSR involved the consolidation of many smaller municipalities which meant that staff became employees of larger organizations which in some cases brought increased and competitive salaries. In addition the downloading of services opened up opportunities in other service areas such as social housing aside from social assistance. Larger departments with increased staffing levels and increased levels of responsibilities for multiple programs also resulted in the proactive allocation of resources, such as the creation of policy and program planning departments in some municipalities. These types of changes, while not documented in literature, may have indeed expanded the opportunities for social workers in municipal services delivery (Schuster, 2009).

Introduction of the Ontario College of Social Workers and Social Service Workers (OCSWSSW)

In 1998 the Social Work and Social Service Act was introduced and received proclamation on August 15, 2000. The most notable impact of its establishment was the inability of social workers to utilize the title of "social worker" unless registered with the 
college. Infractions are at a cost of five thousand dollars for first offenses and up to ten thousand dollars for subsequent offenses. Interview participant, Dick Stewart recalls when this occurred and believes that the implementation approach by the College was authoritarian and may have made greater inroads with welfare administrators if it had been more pro-active and supportive in how the changes were implemented.

Retrospectively the college could have met with welfare administrators to discuss the changes, perhaps offer transitional periods for staff to acquire their registrations, but this did not happen. Welfare administrators felt the heat and many were not happy. Staff that held the specific titles and associated degrees or diplomas were looking to their municipal employers to "foot the bill" for registration. Stewart believes that in most cases, the job titles of existing social workers in the field were altered as necessary (i.e. case manager, income support worker) to ensure that that they were not in violation of the new act and therefore not using the title of social worker. Stewart is not aware of any welfare administration offering to pay the registration fee for its employees.

Notably, social workers employed in social assistance may have chosen to register with the college, but as a "field of practice" social assistance was absent from its affiliation with the college. This may have been a lost opportunity for both the profession and the field and in retrospect a different implementation strategy on behalf of the OCSWSSW may have led to a partnership as opposed to a parting of ways. I am suggesting that perhaps the OCSWSSW in advance of implementation could have connected and / or struck a partnership with Administrators of Social Assistance or the professional association, OMSSA. Through such a partnership recognition could have been given to 
those in the field of social assistance that would have met the criteria for the newly

formed college. The partnership could have been pro-active with the College and field of practice strategizing how to gradually get staff registered. Instead the Administrators of

Social Assistance who felt the pressure simply altered staff titles.

\section{Organizational Culture}

Every workplace regardless of its functions, maintains and perpetuates its own

"organizational culture". Organizational culture is defined as:

...simple way of looking at organizational culture is to view it as a group's general reaction to stimulus. An organizational culture is a group of people who have been trained, or who simply have learned by those around them, how to act in any given situation. In this way, corporate culture functions just as any social learning does. The other aspect of organizational culture that is often true is that it becomes very deeply rooted. It is the identity of a company, and because of that, in some ways it becomes an identity of those who work there, as well. This is always important to remember, as culture becomes like a circular argument. The people end up affecting the culture as much as the culture is affecting them. (web resource, 2010)

An organizational culture develops over time and is most influenced by its history, management approach and by its employees. Each municipal social service office in Ontario would have its own unique organizational culture. However, I have discovered over many years and through provincial networking opportunities, there is a bond, common language and arguably similar organizational culture amongst many staff working in municipal social services across Ontario. It is this culture that plays a strong role in both the reality and the perception of who works in the field of social assistance. Through participant interviews and literature reviews it is believed that the profession of social work has not historically or presently had any significant influence upon the qualification of those that deliver municipal social services. 
If the profession of social work and the employment of professional social workers had been desirable in the administration of social assistance many years ago, it would be far more likely that the organizational culture of social assistance today would be different. I envision that if social work had a greater role in social assistance, that the staffing and programs would be more holistic and more client centred and greater advocacy internally for changes in regulations. Interview participant, Hugh Drouin spoke of the missed opportunities in the 1940s; missed opportunities for a profession that had minimal numbers of graduates and with only MSW options and a field of practice that had no choice but to hire outside of the profession. While there was a strong push for more schools of social work, the government did not respond quickly to the demand.

The perpetuation of the organizational culture of social assistance is not limited to municipal government leaders and municipal staff but is also influenced by the profession of social work, the clients of social assistance, municipal politicians, provincial legislation, social workers in the community, community agencies and university professors. Each group may influence organizational culture of social assistance in either a positive or negative fashion, but the key point to be made is that the field of practice alone is not responsible for the culture that has developed.

\section{Technology and Social Assistance}

The introduction of technology has been cited by three of the interview participants and while not discussed in scholarly material, it has become clear that technology may have a contributing role in the relationship between social assistance and social work. Prior to 
the Conservative Harris government, technology was not in place to support the function of case management to the extent it is available today. What did exist prior to Harris is what was commonly known as the Client Information Management System (CIMS) which was a data input program to mainly produce cheques and offer information throughout Ontario on terminals if someone was receiving social assistance benefits in another area. The practice of completing applications via the computer did not come until 1996 at which time Caseworker Technology (CWT) was introduced. About 1 year after CWT came into place, the Ontario Works Technology (OWT) which assisted in monitoring client's employment based activities was introduced. The implementation of these two computer-based programs, signaled for many municipalities the end of homevisits as a method of service delivery. The casemanagers became more "office bound" and for some including me, the casemanager role evolved to be more administrative.

At the Social Services Restructuring Conference, Toronto, 1996 and as reflected in the report No More Cap-In-Hand, the issue of technology is discussed. The report highlights that with technology and automation entering the field of social assistance that workers who previously required the skills for dealing with challenging problems of recipients were being diminished to clerical and data processing functions (National Union of Public and General Employees, 1996). While the report makes this statement, it is also important to remember that those members of society who received social assistance at that time did not change when CAP ended. The technology in 1996 and the technology of 2010 is not able to replace true case management with respect to assisting and supporting 
clients through difficult life circumstances. The suggestion that the introduction of technology downgraded the required skills of social assistance workers, may suggest that the understanding and respect for the work in this field of practice may not have been there to begin with. The dichotomy is that Ontario Works brought the larger basket of options to clients, but the accompanying technology inhibited the flexibility that staff had previously to engage in true case management.

In 1998 the Harris government entered into a contract with Andersen Consulting to build a new comprehensive technology program to support the administration of social assistance in Ontario. The resulting system which was implemented in 2001 was called "Service Delivery Model Technology" (SDMT) and it has been criticized by staff and municipal leaders for the complexity that it has brought to the social assistance program, in addition to the original price tag of the system which was estimated at hundreds of millions of dollars. Interview participant, Allan Moscovitch comments that:

The social assistance system is about helping people find their way through the conditions of modern life.... a variety of conditions results in a variety of needs and thus requires judgement. If social assistance staff are not able to exercise judgement, then the range of alternatives is too limited. Social assistance needs people that can exercise judgement and computers cannot do this. (Moscovitch, 2009)

In this modern age, it is important to note that it is not only social assistance that has seen the activity of casemanagement come into the world of computers. Social work activities such as child welfare and children's mental health also have had to adjust to computerization and thus to suggest that social assistance technology has impacted social workers wanting to work in the field of social assistance would be an exaggeration. It is believed that the introduction of technology into social assistance may be just one of the 
factors that has contributed to a less than positive perception of the field and the work done by staff.

\section{The Dual Purpose of Social Assistance}

Interview participants, Allan Moscovitch and Dick Stewart both allude to the dual purpose of social assistance as contributing negatively to the involvement of social workers in the field of social assistance and the recruitment of social assistance agencies of trained social workers. If the purpose is to collect information and issue funds then it is reasonable to consider that clerical trained staff would meet the need. If the purpose is to go beyond just the issuance of funds and to support and coach clients to self sufficiency regardless of the singular or multiple issues they must resolve, then the necessary competencies are arguably in the domain of social work. Not unlike most of the other provinces in Canada (with the exception of Quebec) Ontario has a social assistance system that has a dual purpose. It attempts to both coach and support the needs of its clients while also managing and issuing financial support. Moscovitch suggests that this duality becomes problematic when not well balanced.

During the varying philosophical and political changes that social assistance has gone through over the last several decades, there have been long periods in which only the financial purpose has been emphasized. With a dual purpose, Moscovitch suggests that there will always be a tendency in social assistance for the financial issuance of benefits to come before the social support and counseling of clients. I recall a time as a front line case manager and how during the recession of the 1990s with caseloads at an all time 
high, the focus was on the issuance of financial benefits because as there was no time for anything else. During stressful times (i.e. new policies, recession, high caseloads) the financial tasks of social assistance delivery will always rise to the top and it is these times and the inability to control the unequal nature of this balancing, that may result in trained social workers not wanting to work in social assistance.

In an economy driven by the private market, the welfare of the citizens are usually always at the mercy of the prevailing economic and ideological conditions of the times. That is, when the economy is stressed, there will be less provision to this group of people...this is the case even when we consider that during economic recessions, life becomes more difficult for the impoverished. Thus, the system abandons them when they are most in need. In more welfare state oriented economies (i.e. Scandinavian countries) this doesn't happen to quite the same extent although it still happens. Esping- Andersen as cited in Chapter 3 identified Canada as having a liberal welfare state regime, one that struggles to meet the needs of its impoverished in challenging economic times (Esping-Andersen, 1990).

This dual purpose and the conflict that it has brought to the role of social workers is discussed in previous chapters of this thesis. The dual purpose conflict or contradiction was identified in the 1920 s by Mary Richmond, the original author of case management, and its continuation is a result of the political economic realities of an environment where social assistance remains at the bottom. The state has undervalued the provision of social support for social assistance clients and the profession sees the "determination of 
financial eligibility as "beneath" its skills and competencies is in a difficult dilemma. This divide and tension between the dual purposes assists in providing insight into what may be irreconcilable differences between the profession of social work and the field of social assistance. I believe that these tensions are reconcilable but the challenge is that the social workers are either already gone from the field or they were never really there. Thus while the tensions may be resolvable, the field of practice and the profession of social work may have already moved to far down their separate roads to find each other.

\section{The Role of Social Workers}

Figuring out the numbers and prevalence of social workers actually working in the field of social assistance is a very difficult challenge. The municipal administration of social assistance across forty seven "Consolidated Municipal Services Managers" (CMSM) each with its own hiring standards guarantees that this question cannot be answered with any validity. The interview participants all reported differing approaches to the recruitment of staff, some with a preference for social work education and others with minimal to no priority for social work educated applicants. Over many years the educational background of staff administering social assistance has had a more direct correlation with the flavour of local municipal councils and senior staff decisions rather than with any provincial standards or lack thereof.

Interview participant Hugh Drouin, Commissioner of Social Services for Durham, states that his municipality does seek out social workers to hire in social assistance. Drouin describes two key areas of the municipality's services that require social work degrees. The first is their Division of Family Services which offers counselling, mediation and 
other services; most of the staff in this area have a BSW or MSW; and second is front line case manager services. Drouin believes that the skills of social workers are extremely relevant in the delivery of social assistance and in addition to himself, the Chief Administrative Officer of Durham County is also a trained social worker. He indicated that his support of the profession of social work is reflected by his actions to hire social workers for various positions in Durham County.

Interview participant, Mike Schuster of the Regional Municipality of Waterloo notes that there are two key areas within his organization in which professionally trained social workers are recruited. The first is in the social work unit which screens new applicants for social assistance and the second area is social planning. Schuster notes that social work graduates may also be hired for regular casemanagement positions but often such positions may be filled with graduates of the social service worker program from their local community college. In terms of post secondary placements for social work students, Schuster stated that while the area of social planning is popular, they receive little interest in social work placements in the area of front line work.

Drouin spoke to the issue of universities and their role in influencing social work graduates into fields of practice. He believes that social assistance is not promoted as an option for graduates and that many students may not give it a second thought. Drouin believes that schools of social work are not adequately preparing students for leadership roles; roles that can and do exist in the field of social assistance. He advocates that schools of social work need to model social work for their students and ensure that all of 
the options are presented and that the vision is not too narrow. Drouin views the ideal skill set of social workers as being broad and flexible and that the true range of practice options is limitless. Interview participant Allan Moscovitch, a professor at Carleton University, recalls only three students over the past several years that expressed an interest or intent in working in the field of social services.

The title of "social worker" does not always mean the same thing to all people. I have prepared this thesis with a narrow meaning; that being a university educated social worker. While titles may be often dismissed as merely bringing attention to academic qualifications, it might be suggested that the profession of social work has not done its job in laying claim to the title of social worker and clearly identifying to society who the social workers are. In my experience several social service workers with college diplomas identify themselves as "social workers". University educated social workers are sometimes made to feel guilty about pointing this out and they are accused of "looking down" on the college credential. I would argue that this is not necessarily the case. Is it wrong to expect different forms of education to claim different areas of work? Would the professions of law, education and medicine accept this? It would be considered inappropriate for anyone to identify themselves as a doctor, a lawyer, a psychologist, a nurse or tradesperson if they did not hold the relevant qualifications. Then why has it become acceptable for the term social worker to be used without such regard for qualifications? The answer resides in the complex history of social work's identity formation and the delicate balance of supply and demand coupled with the action and non-action of the professional body. 


\section{Duality of Social Work: A Detriment or an Advantage}

Canadian students of social work have had available to them many options with respect to their programs of education. They can choose from several universities, select a program focus, and customize a course schedule to match long term career goals. Several social work programs have developed reputations based on their particular areas of focus such as more clinically focused, oriented to community development or centred on policy and administration. These many faces of social work practice and training may have helped to create diversity and options but it may have also contributed to an identity crisis of a profession and its professionals. Moscovitch is clear to note that he does not view social work as a variation of psychology and it is not just about clinical counseling. As a social work educator he promotes and supports a wider view of social work purpose and functioning. The question that arises for me, is whether there is a divide within the profession regarding the various streams of social work education: are some more valued than others? If there is a divide, is it possible that social workers themselves contribute negatively towards a narrow view of social work practice? While this question cannot be competently answered at this time, it is thought provoking. I maintain that professional social workers have their own views about what constitutes social work and their views are influenced by their personal experiences in the field and their education.

The Canadian Association of Schools of Social Work Education (CASWE) is a national non-government organization of educational institutions whose purpose is to advance social work education in Canada. The mission statement of the CASWE includes the following statements: 
The association views social work education as a critical process based upon dialogue which respects difference and diverse sources and forms of knowledge and skills and encourages dissent.... the CASWE stands with populations which experience poverty, exploitation and domination, and which engage with us to promote change and achieve equity and social justice through social work education, scholarship and collective action. (CASWE, 2010)

The above goals of the CASWE are not clear to me as a social worker. I am left with the impression that as a student in social work education what I learn and what I focus upon will be my personal decision. An education that is based on dialogue and encourages dissent is not a strong argument for why someone would pay tuition to partake in social work education. I have been a student of social work for several years and I have had an amazing opportunity to learn and grow as a social worker, but I think the social work profession needs to more clearly define what it is, concretely, that it has to offer students. Flexible programming is desirable but it is important that it does not risk compromising the profession of social work. The mission statement also identifies that it stands with populations which experience poverty, exploitation...how does this happen? Does the CASWE have its finger on the pulse of poverty in Canada? If so, how does this translate into the education that it supports through universities offering social work programs? The statement that it makes serves to separate the issue of poverty as being different from exploitation and domination... a view that appears short- sighted in that poverty is not an experience, but rather an unfortunate reality of our eroded welfare state. I suggest that the CASWE needs to ensure that it clearly articulates a mission that is representative of all schools of social work, social work students and the population that it proposes to "stand with". 


\section{Chapter Nime: Conclusions}

This thesis has identified some of the main political, economic and ideological shifts in society over the past ninety years and the corresponding impacts of this upon the profession of social work. The early social workers of the Charity Organization Societies emerged out of the societal need to help the poor. These early beginnings served as the roots of a profession that has evolved to the modern day. The evolution of social work as a profession has not been an easy road. In some respects it seems to still be in the midst of an identity crisis; defining what it is that social workers do, what it is that they believe and who it is that they serve. This rocky evolution has resulted in the field of social assistance being sidelined within the profession and social workers not being sure if work in social assistance is even with the purview of the profession. Apart from the early days of the COS, social workers and the profession of social work have never seriously embraced the poor.

The social work undertaken by the Charity Organization Societies and the Settlement House Movement encompassed the whole person in an effort to relieve the impacts of poverty. Although neither the COS nor the Settlement workers were working under the auspices of professional social work practice as we know it today (this developed only in the mid-twenties) they worked with the poor as volunteers. The process of professionalization it appears, tended to develop workers that worked with certain aspects of a person's life and not the entire person. Thus, as the profession of social work evolved it has become somewhat fragmented and in that process poverty has been ignored; no longer does the profession of social work endeavour to meet the needs of 
people holistically. This fragmentation of social work created fields such as child welfare, community development, hospital social work and mental health work. Most of these fragments contain elements of poverty. Poverty typically transcends other social and individual problems with which social workers come in contact, yet there is no distinct setting in which social work has established itself to deal directly with poverty and the victims of poverty.

It is the finding of this thesis that the profession of social work has dropped the work of social assistance; it has cleansed itself of this complex and difficult employment. This is not entirely surprising since social workers are products of their society. From a political economy perspective, it can be argued that what we see happening is a "mirroring effect". In a society that does not value the underclass largely because it is regarded as nonproductive; a society that continues to blame the poor for their economic situation; and an environment that makes the work of social assistance unattractive and difficult, it is to some extent not surprising that this perspective is mirrored in the social worker, and in schools of social work who educate social workers. The poor in some respects may be casualties of a profession that places more emphasis on attaining and maintaining professional status than it does on working with the most desperate elements of society.

Working with the whole person is hard and in the case of social assistance, it is not easy to know where to begin when the person in front of you is afflicted with mental health issues, has lost her children to Children's Aid, struggles with anger management and lives in poverty. In these circumstances it is clearly insufficient to simply hand over some 
funds. The way state services are structured, this individual's issues are each dealt with separately - the health care system, Children's Aid Society, anger counseling services and social assistance. The fact that poverty permeates all of these is left aside.

The disdain that the current state has exhibited for its impoverished is likened to the rejection that the field of social assistance has experienced from the profession of social work, which can also be likened to the internal conflict of social workers themselves. This thesis has highlighted the struggles of identity that have historical roots for the social. work profession and its members. Like others members of society, social workers are driven by prestige in which people make value judgments about each other, and while this can be very subjective, the work of social assistance is not in the realm of prestigious. There are many other forms of social work that do have prestige and these do not serve the poor. Thus if the state does not value the work done to assist those in poverty, and society and peers do not acknowledge the value through prestige, it only further supports the findings of this thesis.

It is not only the clients of social assistance that face the stigma of poverty but it is also the staff of social assistance that are stigmatized. Conservative ideology blames the poor for their situation and society views those in poverty as just not "helping themselves." This view continues to be perpetuated and is evidenced among social workers who do not see the work of social assistance as desirable and, as this thesis has noted, many social workers believe that their skills and competencies exceed those that may be necessary in this type of work. I do not support this, but I am cognizant that this reality is just a small 
microcosm of what is actually happening in the larger society. The poor are stigmatized for their non-participation in the market economy, they form the underclass and the social workers that work to assist them have become part of the underclass within their own profession. The work of social assistance is often regarded as one of the least desirable areas of work.

Ontario has been strongly influenced by conservative governments for many years and coupled with several periods of economic recession, this has negatively influenced any potential partnership between the profession of social work and the field of social assistance. Ontario is the only remaining province to administer a two-tier system of social services in which $O D S P$ is administered by the province and Ontario Works is administered by municipalities. This two-tier system has enabled the continuation of the original Elizabethan Poor Laws in which the poor were categorized as "worthy" and "unworthy". In my opinion the Ontario government has identified through its policies and legislation that Ontario Works is a program for the unworthy poor. Ontario Works represents a program of meager financial and social supports, while the ODSP program offers higher financial benefits, greater employment supports and higher assets limits to mention only a few differences.

The relationship between social assistance and the profession of social work is a tenuous one. Influential pioneers such as Whitton, Heise, Cassidy and Marsh all attempted to link the two, but with little success. I believe that the partnership, if strong and mutual, could have undeniable benefits to social workers, the profession of social work, to 
municipalities, the province of Ontario and, most importantly, to clients of social assistance. The research of this thesis suggests that work in social assistance has been forfeited for political and economic reasons. Recipients of social assistance are in many ways the least enfranchised members of society; people in need of financial resources typically have little political power. This, combined with the difficulty of the work, the low self esteem and stigmatization that is held by some social workers, and a government that is intent on cutting costs by reducing social assistance work to "form completion" have contributed to eroding the work of the welfare worker. This does not mean that social work skills are not required in the work of social assistance. In fact, the contrary is true. Experience has shown that people living on the margins of society often have complex, multiple issues with which they are dealing. The short sightedness of governments and universities to recognize the interrelatedness of these issues and the lack of attention given to them will undoubtedly surface in the future. There does not appear to be any chance of a revived partnership in the near future, but that does not mean that social workers who remain in the field cannot strive for such progress and recognition of their work.

One factor to consider in this discussion is the political reality of municipal social services. The involvement of municipalities in administering forms of social assistance to its residents in need has been firmly established for over a century. The financial and ethical responsibility for social assistance between the three levels of government has varied over time. The front line community reality of municipal government has 
invariably demanded it address and serve its citizens in need, regardless of provincial or federal support. Is social assistance rightly placed as a municipal responsibility?

Ontario remains as the only Canadian province to administer social assistance municipally. In light of Ontario government announcements in 2008, the costs of municipal social assistance will be gradually uploaded $100 \%$ to the province over the next several years and be fully complete by 2018 . While the province has assured municipalities that it still sees them leading the administration and delivery of social assistance, John Stapleton (2010) is more skeptical. Stapleton notes that there have been other examples in Canada of provinces (Manitoba, Nova Scotia and British Columbia) that intended to maintain municipal delivery of social assistance, but inevitably the programs evolved to be provincially administered. This may be the fate of Ontario municipal social assistance, but will not be confirmed for many years.

In the event that social assistance was to be provincially administered, I would foresee an opportunity to standardize the staff training requirements provincially, however I cognizant that this is not likely given that the provincial $O D S P$ has not sought social workers in its provision either. If social assistance remains as a program provided by the forty seven CMSM's in Ontario, I anticipate that the status quo will remain; in which some municipalities will employ university trained social workers, while others may not.

The interviews conducted as part of this thesis were telling in that the profession of social work has never been strongly or universally accepted as part of the field of social 
assistance. While there were a few examples in which active recruitment for social workers takes place, these appear to be limited and in some cases significantly influenced by its municipal leadership.

The approach to social assistance in Ontario and the ideological base that underlies it, has changed just like the economy and politics within the province of Ontario over the decades. The work of social assistance meets the CASW definition of social work as identified in this thesis (Appendix I.). However, social assistance has not been able to claim a clear and solid space in the profession. The field of social assistance has been filled with non social work educated personnel during period of high social work demand and short supply. This begs the question: if the majority of staff employed in social assistance are not trained in social work, does this mean that social work training is not essential?

In the desire to establish itself as a recognized profession, Social Work has not overtly embraced the field of social assistance. While history places the profession in the early developments of social assistance, the development of the welfare state and the growth of the profession over the past ninety years appears to have been relatively independent of each other. There have clearly been intersections upon which the profession and field of social assistance have connected and found mutual benefit, but not to the point that the profession identifies with such. It is important to note that the profession is not only represented by national or provincial associations, but in a much broader way by those educated in Social Work. 
This thesis was undertaken with a definition of "social worker" that excluded those without a BSW, MSW or Doctorate of Social Work. One of the unanticipated emerging themes was the differing viewpoints and definitions of a social worker. The researcher's underlying bias was that a social worker must be university educated in the field of social work, however reference to social workers in the literature and even some of the interviews was broader and more general in its definition. Recent studies such as "In Critical Demand" (2001) fail to delineate the educational levels as distinguishing roles in the social services and social work. Social service worker programs at local community colleges often encourage their students to identify as social workers. While I am surprised by this loose use of the title social worker, it is clear that this is embedded in the history and the very nature of the work. The lack of integrity in the title of social worker is seen as having a current and continued negative impact upon the profession of social work, not only in the administration of social assistance but in general.

Bertram Beck in the conclusion of his 1981 article "Social Work's Future: Triumph or Disaster" suggests that the profession of Social Work needs to be globally minded as it moves into the future. Beck predicted that our economy would continue to move mass production to developing countries and with capitalism in full force that social work values would become critical in counteracting an exploitive society and ensuring that society continue to respect the needs of its people. In 1981 Beck extended the following caution and advice:

It is necessary for social work to keep alive its fundamental commitments and act upon them: to avoid putting the well-being of the profession over the well-being of people. (Beck, 1981) 
It is now twenty eight years after this cautionary note by Beck and it is equally as valuable to be repeated in 2010. Private practice is one of the many areas of social work that seems to be attractive for professionally trained social workers while more traditional areas such as working to address poverty and the area of social assistance are less attractive. Why is social assistance work less attractive? Perhaps it is the salary, the stigma attached to it, the difficulty of the work, the clientele or a combination of all these factors? Some authors, as cited in the literature review, believe in the moral obligation of trained social workers to extend their services to the work of poverty and certainly the Social Work Code of Ethics supports this, yet this is not reflected in the current reality as it pertains to the work of social assistance.

In the following quotation, Wyers (1983) provides a description of the work done by a public welfare worker and while this is from a 1983 article, it remains astonishingly relevant and accurate today. In this quote Wyers has captured the very essence and purpose of why this thesis was undertaken:

The income maintenance line worker makes important decisions about the eligibility of applicants who contact him or her for benefits. To make these decisions, the line worker should understand human development, have both an intellectual and emotional awareness of the effects of poverty, be astute in understanding the plight of the aged and the disabled in society, understand the complexities of human functioning, and be able to detect all areas of a applicant's needs. These needs are more than financial, and the worker needs to view the applicant a an entire person, not simply one who may or may not be eligible for assistance from the income maintenance agency....certain analytic and service functions cannot be separated from the overall activities of the worker. (Wyers, pg.261)

History continues to move forward and perhaps on the road ahead the profession of social work and the field of social assistance will meet and discover the reciprocal benefits that they have to offer each other. 


\section{Appendix : Definitions}

Several terms used in this paper have had varying definitions across regions and over the

course of history. To ensure consistency in this study, the following definitions have been used:

- Social Work (Profession/areas of Practice): \{CASW definition\} Work is a profession concerned with helping individuals, families, Social groups and communities to enhance their individual and collective well-being. It aims to help people develop their skills and their ability to use their own resources and those of the community to resolve problems. Social work is concerned with individual and personal problems but also with broader social issues such as poverty, unemployment and domestic violence. Human rights and social justice are the philosophical underpinnings of social work practice. The uniqueness of social work practice is in the blend of some particular values, knowledge, and skills, including the use of relationship as the basis of all interventions and respect for the client's choice and involvement (CASW, 2009)

- Social Worker: There are a variety of ways in which the term of social worker is described. For the purpose of this thesis a social worker will include and be limited to an Individual that has completed university education in the field of Social Work and has obtained a BSW, MSW or DSW.

- Social Assistance: A program that administers basic food and shelter allowances to residents of Ontario who are eligible in accordance with the current Ontario Works Act and the former the General Welfare Assistance Act. Additional terms that are used interchangeably include welfare, relief and income maintenance.

- Ministry of Community and Social Services (MCSS): a branch of the Ontario Provincial Government that has specific responsibilities for the oversight and accountability of various acts and regulations. Specific to this thesis, the MCSS is the provincial authority for the current Ontario Works Act and the former General Welfare Assistance Act. 


\section{Appendix B: Abbreviations}

CASW: $\quad$ Canadian Association of Social Workers

COS: Charity Organizational Society

GWA: $\quad$ General Welfare Assistance Act

ODSP: $\quad$ Ontario Disability Support Program

OASW: Ontario Association of Social Workers

OCSWSWW: Ontario College of Social Workers and Social Service Workers

OW: Ontario Works

MCSS: Ministry of Community and Social Services

CMSM: Consolidated Municipal Services Manager

LSR: Local Services Realignment

OWOA: Ontario Welfare Officers Association

DSSAB: District Social Services Administration Board

OMSSA: Ontario Municipal Social Services Association

LICO: Low Income Cut-Off

CAP: $\quad$ Canada Assistance Plan

CHST: $\quad$ Canada Health and Social Transfer

CST: $\quad$ Canada Social Transfer

NCCSSW: National Committee of Canadian Schools of Social Work 


\section{Appendix $\mathbb{C}$ : Letter of Introduction}

\section{Carleton \\ UN $\mathrm{O}$ VRSHTY \\ Camada's Capital University}

Letter of Information and Consent Form

June 16,2009

Dear Sir / Madame:

My name is Alison Tutak and I am a Masters of Social Work student at Carleton University, Ottawa and I am currently working on a thesis project. The thesis will examine the role of the profession of social work in the delivery of municipal social assistance in Ontario. The thesis will examine key factors that have influenced social assistance policies and what impacts that has had on the profession of social work. The thesis supervisor for this project is:

Dr. Therese Jennissen

School of Social Work

Carleton University

Ottawa, Ontario

Email: therese.jennissen@carleton.ca

I am contacting you specifically because of your current or previous role as a social assistance Administrator in Ontario and believe that your experiences, insights and knowledge will significantly inform the research of this thesis. I am contacting 4-5 potential participants for this study. You are asked to participate in an open ended interview that may take 30 to 45 minutes in length. In addition you are asked to serve as a subject matter expert throughout the work of this thesis to provide information or clarification that may be required by the researcher. I do not anticipate that you will experience any risk by your participation in this study.

In consideration of the nature of this project, I am not able to guarantee anonymity to participants. However, all steps will be taken to ensure due diligence in the handling of information and this will include: information that is gathered will not at any time be provided to a $3^{\text {rd }}$ party and will strictly remain with myself as the principal researcher in a locked personal filing cabinet. In addition, interview notes will be retained for a one year period following the completion of the thesis and after the one year period the notes will be shredded. 
You have the right to withdraw from the project at any time and if you chose to do so, all information previously provided would be destroyed upon your request. The final thesis will be available at Carleton University Library. This thesis research project was reviewed and has received clearance by the Carleton University Ethics Committee. If you have any concerns or questions about your participation in this research, please contact the Chair of the Carleton University Ethics Committee:

Professor Antonio Gualtieri, Chair

Carleton University Research Ethics Committee

Office of Research Services

Carleton University

1125 Colonel By Drive

Ottawa, Ontario, K1S 5B6

Tel: 613-520-2517

E-mail: ethics@carleton.ca

Contact Information of student: Alison Tutak:

Alison Tutak

Masters of Social Work Student

Social Work Department

Carleton University

Ottawa, Ontario

atutak@connect.carleton.ca

Thank you for your participation in this project.

Signature of Researcher

Date

Signature of Thesis Supervisor

Date

Consent:

$\mathrm{I}$, have read the above letter and understand that I am participating in a thesis research project and I voluntarily agree to participate. 


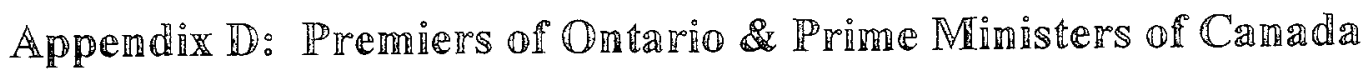

\begin{tabular}{|c|c|c|}
\hline Year & $\begin{array}{l}\text { Premier / Political } \\
\text { Party }\end{array}$ & $\begin{array}{l}\text { Prime Minister / } \\
\text { Political Party }\end{array}$ \\
\hline $\begin{array}{l}1917 \\
1919 \\
1920\end{array}$ & Ernest Drury (Farmer) & $\begin{array}{l}\text { Wilfrid Laurier (Conservative) } \\
\text { Robert Borden (Conservative) } \\
\text { Arthur Meighen (Conservative) } \\
\text { McKenzie King (Liberal) }\end{array}$ \\
\hline 1923 & George Ferguson (Conservative) & \\
\hline 1926 & & $\begin{array}{l}\text { Arthur Meighen (Conservative) } \\
\text { McKenzie King (Liberal) }\end{array}$ \\
\hline 1930 & & Richard Bennet (Conservative) \\
\hline 1934 & Mitchell Hepburn (Liberal) & McKenzie King (Liberal) \\
\hline 1942 & Premier Gordon Conant (Liberal) & \\
\hline 1943 & $\begin{array}{l}\text { Premier Harry Nixon (Liberal) } \\
\text { Premier George Dean } \\
\text { (Conservative) }\end{array}$ & \\
\hline 1948 & $\begin{array}{l}\text { Premier Thomas Kennedy } \\
\text { (Conservative) }\end{array}$ & Louis St. Laurent (Liberal) \\
\hline 1949 & $\begin{array}{l}\text { Premier Leslie Front } \\
\text { (Conservative) }\end{array}$ & \\
\hline 1957 & & John Diefenbaker (Conservative) \\
\hline 1961 & $\begin{array}{l}\text { Premier John Robarts } \\
\text { (Conservative) }\end{array}$ & \\
\hline 1963 & & Lester Pearson (Liberal) \\
\hline 1968 & & Pierre Trudeau (Liberal) \\
\hline $\begin{array}{l}1971 \\
1979\end{array}$ & $\begin{array}{l}\text { Premier William Davis } \\
\text { (Conservative) }\end{array}$ & Joe Clark (Conservative) \\
\hline $\begin{array}{l}1980 \\
1984\end{array}$ & & $\begin{array}{l}\text { Pierre Trudeau (Liberal) } \\
\text { John Turner (Liberal) } \\
\text { Brian Mulroney (Conservative) }\end{array}$ \\
\hline 1985 & $\begin{array}{l}\text { Premier Frank Miller } \\
\text { (Conservative) } \\
\text { Premier David Peterson (Liberal) }\end{array}$ & \\
\hline
\end{tabular}




\begin{tabular}{|c|c|c|}
\hline 1990 & $\begin{array}{l}\text { Premier Bob Rae (New } \\
\text { Democratic) }\end{array}$ & \\
\hline 1993 & & $\begin{array}{l}\text { Kim Campbell (Conservative) } \\
\text { Jean Chretien (Liberal) }\end{array}$ \\
\hline 1995 & $\begin{array}{l}\text { Premier Mike Harris } \\
\text { (Conservative) }\end{array}$ & \\
\hline 2000 & & \\
\hline 2002 & Premier Ernie Eves (Conservative) & \\
\hline $\begin{array}{l}2003 \\
2006\end{array}$ & $\begin{array}{l}\text { Premier Dalton McGuinty } \\
\text { (Liberal) }\end{array}$ & $\begin{array}{l}\text { Paul Martin (Liberal) } \\
\text { Stephen Harper (Conservative) }\end{array}$ \\
\hline 2008 & & \\
\hline
\end{tabular}

* source of information for the above chart is www.wikipedia.org 


\section{Appendix $\mathbb{E}$ : Open $\mathbb{E}$ inded Honterview: Discussion Probes}

\section{Open Ended Interviews: Discussion Probes}

The following points have been prepared as discussion probes for the qualitative interviews that will be completed with current and former social assistance administrators. The discussion probes will serve as a tool for the researcher only and will not be directly provided to interview participants. The interview participants will also be advised of the definition of social worker that is being used in the context of this research. The definition of social worker is an individual that has completed either a BSW or MSW degree.

- What part of Ontario did you work as a social assistance Administrator and was this area rural or urban in nature?

- Were you in the role as a municipal social assistance Administrator in more than one area within Ontario and if yes, where was this?

- How many years did you work in the position of Municipal Social Assistance Administrator and did you hold other positions within municipal social assistance prior to taking the position of Administrator? If yes, what were these positions and how did these previous roles influence you in the role of Administrator?

- What is the approximate number of staff in your department that are / were involved in delivery of social assistance?

- During your time in municipal social assistance what were some of the provincial changes (legislative or other) that you found the most challenging. Can you identify specific changes that you recall being specifically significant during your tenure (such as change in governments or legislative changes)?

- In regards to political eras (Petersen, Rae, Harris, McGuinty) did you notice any trends during these periods in regards to social assistance policy and program changes?

- What were some of the changes that you felt were positive and why and what may have been changes that you feel were negative or detrimental to the Ontario social assistance program?

- What were some of the changes/directions by your municipal council that posed challenges \& also changes / directions by municipal council that were positive

- How do you / did you perceive the role of municipal council in the delivery of social assistance. (i.e. - progressive/ advocacy role or conservative)?

- Do you have any examples to share in which your municipal council took action (advocacy, resolutions, legal or other) against provincial changes to the social assistance program?

- Do you recall any key documents / events that significantly impacted social assistance?

- Did you / do you have trained social workers (BSW or MSW) working in your department and did you / do you purposely seek social workers in your 
recruitment processes during hiring. Why or why not? Was this a shift from previous eras? Explain?

- During your time - were there any trends that you noticed in terms of the recruitment or departure of social workers in social assistance \& do you have any insight or thoughts on why?

- What do you think social workers might contribute to the field of social assistance? In your opinion, is this a change from earlier eras?

- Do you feel that the skills of social workers are relevant and utilized (currently or in the past) in the administration of social assistance?

- Are there other disciplines / skills / training that you feel are more relevant to have in the staff acquired to work in the field of social assistance...... if yes, what are these?

- Given the various roles within social assistance (caseworker, management, administrative) - what area do you feel is most conducive to social workers and the skills they have?

- Do you think that there has been any key periods of time and / or events that changed the suitability / relevance of social workers working in social assistance if yes what are these?

- Additional comments / thoughts. 
Appendix F: Ethics Clearance Form

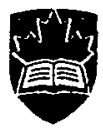

Carleton

UNIVERSITY

Canada's Capital University
Carleton University Research Office

5th Floor Tory Building

1125 Colonel By Drive

Ottawa, ON K15 586 Canada

Tel: (613) 520-2516

Fax: (613) 520-2521

muw.carleton.ca/cu/research/cura/

\section{Ethics Clearance Form}

This is to certify that the Carleton University Research Ethics Board has examined the application for ethical clearance. The REB found the research project to meet appropriate ethical standards as outlined in the Tri-Council Policy Statement: Ethical Conduct for Research Involving Humans and, the Carleton University Policies and Procedures for the Ethical Conduct of Research.

$X$ New clearance

$\square$ Renewal of original clearance

\section{Original date of clearance:}

Date of clearance 28 July 2009

Researcher

Status

Department

Supervisor

Title of project

Alison Tutak

M. A. Student

School of Social Work

Professor Therese Jennissen

The Profession of Social Work and the work of Social Assistance:

Partners or the parting of ways?

\section{Ethics approval expires on: 31 May $\mathbf{2 0 1 0}$}

\section{All researchers are governed by the following conditions:}

Annual Status Report: You are required to submit an Annual Status Report to either renew clearance or close the file. Failure to submit the Annual Status Report will result in the immediate suspension of the project. Funded projects will have accounts suspended until the report is submitted and approved.

Changes to the project: Any changes to the project must be submitted to the Carleton University Research Ethics Committee for approval. All changes must be approved prior to the continuance of the research.

Adverse events: Should any participant suffer adversely from their participation in the project you are required to report the matter to the Carleton University Research Ethics Committee. You must submit a written record of the event and indicate what steps you have taken to resolve the situation.

Suspension or termination of clearance: Failure to conduct the research in accordance with the principles of the Tri-Council Policy Statement: Ethical Conduct for Research Involving Humans and the Carleton University Policies and Procedures for the Ethical Conduct of Research may result in the suspension or termination of the research project.

\footnotetext{
$\vec{L}$

Leslie J. MacDonald-Hicks

Research Ethics Committee Coordinator

For the Chair of the Carleton University Research Ethics Board

Prof. Antonio Gualtieri
} 


\section{Bibliography}

\section{Books, Journals and Government Documents}

Advisory Group on New Social Assistance Legislation (1991). Back on Track. Toronto: Queen's Printer for Ontario.

Advisory Group on New Social Assistance Legislation (1992). Time for Action: Towards a New Social Assistance System in Ontario. Toronto: Queen's Printer for Ontario.

Armitage, A. (1975). Social Welfare in Canada: Ideals and Realities. Toronto: McClelland and Stewart.

Bashevkin, S. (2002). Welfare Hot Buttons: Women, Work and Social Policy Reform. Toronto: University of Toronto Press.

Battle, K. (1994). Poverty: Myths, Misconceptions, and Half-truths. In A. Johnson, S. McBride \& P. Smith (Eds.) Continuities and Discontinuities: The Political Economy of Social Welfare and Labour Market Policy in Canada. Toronto: University of Toronto Press.

Beck, B. (1962). Changing Demands of Practice on the Professional Social Worker. The Social Worker, Volume 31, Number 2, April-May 1963, pgs. 9-15.

Beck, B. (1981). Social Work's Future: Triumph or Disaster? Social Work, Volume 26, Number 5, September 1981, pgs. 367-372.

Bella, L. (1991). Doctors, Social Workers and Nurses. In B. Kirwin (ed.) (1991) Ideology, Development and Social Welfare: Canadian Perspectives $2^{\text {nd }}$ Edition. Toronto: Canadian Scholars Press.

Bowers, S. (1959). The Future of Social Work. The Social Worker, Volume 28, Number 1, January 1960, pgs. 30-47.

Bushbinder, H. (1981). Inequality and Social Services. In A. Moscovitch \& G. Drover (Eds.) Inequality: Essays on the Political Economy of Social Welfare. Toronto: University of Toronto Press, pp. 350-367.

Canadian Association of Social Workers (2009). CASW Presents the Social Work Profession. Retrieved May 4, 2009 from http://www.casw-acts.ca/

Canadian Association of Social Workers (1994). Social Work Code of Ethics. Ottawa: Canadian Association of Social Workers. 
Carniol, B. (1995). Case Critical: Challenging Social Services in Canada $3^{\text {rd }}$ Edition. Toronto: Between the Lines Publishing.

Carniol, B. (2005). Case Critical: Social Services and Social Justice in Canada $5^{\text {th }}$ Edition. Toronto: Between the Lines Publishing.

Cassidy, H. (1945). Public Health and Welfare Reorganization: The Post War Problem in the Canadian Provinces. Toronto: The Ryerson Press.

Cassidy, H. (1945). Unemployment and Relief in Ontario 1929-1932. Toronto: J. M. Dent and Sons.

Cassidy, H. (1943). Social Security and Reconstruction in Canada. Toronto: The Ryerson Press.

Chappell, R. (2006). Social Welfare in Canadian Society. Toronto: Thomson Nelson Publishing.

Cohen, E. J. \& Petten, A. (1997). Sounding The Alarm: Poverty in Canada.

Community Welfare Council of Ontario (1947). Report on the Ontario Conference on Social Welfare. Toronto.

Coward, K. (2000). The History of the Canada Assistance Plan. Ontario: Skyway Printing.

Dare, B. (1997). Harris's First Year: Attacks and Resistance. In D. Ralph, A. Regimbald, N. St. Amand, Open for Business: Closed to People. Halifax, Fernwood Publishing, pp.20-26.

Department of Public Welfare (1954). Conference of District Supervisors, Administrators and Branch Directors. Toronto: The Department of Public Welfare.

Ecumenical Coalition for Economic Justice (1993). Reweaving Canada's Social Programs: From Shredded Safety Net to Social Solidarity. Toronto: Our Times.

Esping-Andersen, G. (1990). The Three Political Economies of the Welfare State. Cambridge: European Univeristy Institute.

Finkel, A. (2006). Social Policy and Practice in Canada: A History. Waterloo: Wilfrid Laurier University Press.

Miller, S. (1963). Max Weber: Selections from His Work. New York: Thomas Y. Crowell. 
Ginsberg, L. (1998). Careers in Social Work. USA: Allyn and Bacon.

Globerman, J. (1992). Regulating Social Work: Illuminating Motives. Canadian Social Work Review, Volume 9, Number 2, Summer 1992, pgs.229-243.

Gough, I. (1981). The Political Economy of the Welfare State. Toronto: The MacMillan Press.

Graham, J., Trew, J., Schmidt, J. \& Kline, T.. Influences on the Subjective Well Being of Practicing Social Workers. Canadian Social Work, pp. 92- 104.

Guest, D. (1997). The Emergence of Social Security in Canada, $3^{\text {rd }}$ Edition. Vancouver: UBC Press.

Grant, J. (1959). Public Welfare - A Major Challenge. The Social Worker, Volume 27, Number 2, April 1959, pp. 5-11.

Grant, J. (1962). Public Assistance and Casework. The Social Worker, Volume 30, Number 2, April 1962, pgs. 4-11.

Gummer, B. (1997). Ethics and Administrative Practice: The Politics of Values and the Value of Politics. In M. Reisch and E. Gambrill (Eds.). Social Work in the $21^{\text {st }}$ Century. USA; Sage Publications.

Haddow, R. (1993) Poverty Reform in Canada, 1958-1978: State and Class Influences on Policy Making. Canada: McGill-Queen's University Press.

Howe, D. (1986). Social Workers and Their Practice in Welfare Bureaucracies. England: Gower Publishing.

Howlett, M. \& Ramesh, M. (1992). The Political Economy of Canada: An Introduction. Toronto: McClelland and Stewart Inc..

Hum, D. (1983). Federalism and the Poor: A Review of the Canada Assistance Plan. Canada, Ontario Economic Council.

Ismael, J. (Ed.). The Canadian Welfare State: Evolution and Transition. Alberta: The University of Alberta Press.

Irving, A. \& Daenzer, P. (1989). Unemployment, Social Work Education, and Social Work Practice: The Need for Creative Responses. In G. Riches \& G. Ternowetsky (Eds.), Unemployment and Welfare. Toronto: Garamond Press.

James, C. (1998). Practical Diversions and Educational Amusements: Evangelia House and the Advent of Canada's Settlement Movement, 1902-09. Historical Studies in Education, Volume 10, Number 1/2, 1998, pp.48-66. 
Jennissen, T. \& Lundy, C. (2009). One Hundred Years of Social Work: A History of the Profession in English Canada, 1900-2000. \{Book: Publishing pending for release $2010\}$

Johnson, A., McBride, S. \& Smith, P. (Eds.) (1994). Continuities and Discontinuities: The Political Economy of Social Welfare and Labour Market Policy in Canada. Toronto: University of Toronto Press.

Johnson, L. (1998). Social Work Practice: A Generalist Approach $6^{\text {th }}$ Edition. USA: Allyn and Bacon.

Keith-Lucas, A. (1992). A Socially Sanctioned Profession? In P. Nelson Reid and P. Popple (Eds.), The Moral Purposes of Social Work: The Character and Intentions of a Profession. Chicago: Nelson-Hall Publishers, pp.51-67.

Kerans, P. (1994). Need and Welfare: Thin and Thick Approaches. In A. Johnson, S. McBride \& P. Smith (Eds.) Continuities and Discontinuities: The Political Economy of Social Welfare and Labour Market Policy in Canada. Toronto: University of Toronto Press, pp.44-56.

Kerwin, B. (Ed.) (1991). Ideology, Development and Social Welfare: Canadian Perspectives $2^{\text {nd }}$ Edition. Toronto: Canadian Scholars Press.

Kopeikin Brill, C. (March 2001). Looking at the Social Work Profession Through the Eye of the NASW Code of Ethics. Research on Social Work Practice, Volume 11, Number 2, March 2001, pp. 223-234.

Leigh, Amy (1964). Viewpoint: On Canadian Social Work and the Changing Times. The Social Worker, Volume 32, Number 2, April-May 1964, pgs. 36-40.

Leslie, D. \& Cassano, R. (May 2003). The Working Definition of Social Work Practice: Does it Work? Research on Social Work Practice, Volume 13, Number 3, May 2003, pp. 366-375.

Little, M. J. (1998). No Car, No Radio, No Liquor Permit: The Moral Regulation of Single Mothers in Ontario, 1920-1997. Toronto: Oxford University Press..

Lundy, C. (2004). Social Work and Social Justice: A Structural Approach to Practice. Canada: Broadview Press.

Macarov, D. (1991). Certain Change: Social Work Practice in the Future. USA: NASW Press. 
McDonald, T. P. and I. Piliavin (1980). Separation of Services and Income Maintenance: The Worker's Perspective. Social Work, Volume 25, Number 4, July 1980, pgs. 259-267.

McGilly, F. (1991). Ideology and Public Assistanc. In B. Kewin (ed.) (1991) Ideology, Development and Social Welfare: Canadian Perspectives $2^{\text {nd }}$ Edition. Toronto: Canadian Scholars Press.

Mishra, R. (1999). Globalization and The Welfare State. USA: Edward Elgar Publishing.

Morales, A. \& Sheafor, B. (1998). Social Work: A Professon of Many Faces $8^{\text {th }}$ Edition. USA: Allyn and Bacon.

Morrison, I. (1997). Rights and the Right: Ending Social Citizenship in Tory Ontario. In D. Ralph, A. Regimbald and N. St. Amand, Open for Business: Closed to People. Halifax, Fernwood Publishing, pp.68-78.

Moscovitch, A. \& Drover, G. (Eds.) (1981). Inequality: Essays on the Political Economy of Social Welfare. Toronto: University of Toronto Press.

Moscovitch, A. (1997). Social Assistance in the New Ontario. In D. Ralph, A. Regimbald, N. St. Amand (Eds.) Open for Business: Closed to People. Halifax: Fernwood Publishing, pp.80-91.

Mullaly, R. (1994). Social Welfare and the New Right: A Class Mobilization Perspective. In A. Johnson, S. McBride \& P. Smith (Eds.) Continuities and Discontinuities: The Political Economy of Social Welfare and Labour Market Policy in Canada. Toronto: University of Toronto Press, pp.76-91.

Mullaly, R. (1997). Structural Social Work: Ideology, Theory and Pratice, $2^{\text {nd }}$ Edition. Toronto: Oxford University Press.

Mullaly, R. (2007). The New Structural Social Work, $3^{\text {rd }}$ Edition. Ontario: Oxford University Press.

Mulvale, J. P. (2001). Reimagining Social Welfare: Beyond the Keynesian Welfare State. Ontario: Garamond Press.

Naiman, J. (1997). How Societies Work: Class, Power and Change in a Canadian Context. Ontario, Irwin Publishing.

NASW Commission on Social Work Practice: Subcommittee on Fields of Practice (1962). Identifying Fields of Practice. Journal of The National Association of Social Workers, Volume 7, Number 2, April 1962, pgs. 7-14. 
National Council of Welfare (1998). Profiles of Welfare: Myths and Realities. Ottawa: Minister of Public Works and Government Services Canada.

National Council of Welfare (1992). Welfare Reform. Ottawa: Minister of Supply and Services Canada.

National Council of Welfare (1997). Another Look at Welfare Reform. Ottawa: Minister of Public Works and Government Services Canada.

National Union of Public and General Employees. No More Cap-In-Hand: Social Services in a Post-Cap Era. Toronto, 1996.

Nelson Reid, P. (1992). The Social Function and Social Morality of Social Work: A Utilitarian Perspective. In P. Nelson Reid and P. Popple (Eds.), The Moral Purposes of Social Work: The Character and Intentions of a Profession. Chicago: Nelson-Hall Publishers, pp. 34-50.

O'Neil McMahon, M. (1992). Responding to the Call. In P. Nelson Reid and P. Popple (Eds.), The Moral Purposes of Social Work: The Character and Intentions of a Profession. Chicago: Nelson-Hall Publishers, pp.173-188.

Ontario Association of Professional Social Workers. Response to "Turning Point: New Support Programs for People with Low Incomes". Toronto, 1993.

Popple, P. (1992). Social Work: Social Function and Moral Purpose. In P. Nelson Reid and P. Popple (Eds.), The Moral Purposes of Social Work: The Character and Intentions of a Profession. Chicago: Nelson-Hall Publishers, pp.141-154.

Ralph, D., Regimbald, A., \& St. Amand, N. (Eds.) (1997). Open for Business: Closed to People. Halifax: Fernwood Publishing.

Reamer, F. (1992). Social Work and the Public Good: Calling or Career. In N. Reid \& P. Popple (Eds.), The Moral Purposes of Social Work: The Character and Intentions of a Profession. Chicago, USA: Nelson-Hall Publishers, pp.11-31.

Reid, N., Popple, P. (Eds.) (1992). The Moral Purposes of Social Work: The Character And Intentions of a Profession. Chicago, USA: Nelson-Hall Publishers.

Regimbald, A. (1997). The Ontario Branch of American Conservatism. In D. Ralph, A. Regimbald, and N. St. Amand, Open for Business: Closed to People. Halifax: Fernwood Publishing, pp. 45-53.

Rice, J. \& Prince, M. (2000). Changing Politics of Canadian Social Policy. Toronto: University of Toronto Press. 
Riches, G. \& Ternowetsky, G. (1989). Unemployment and Welfare. Toronto: Garamond Press.

Riches, G. (1989). Welfare Reform and Social Work Practice. In G. Riches \& G. Ternowetsky (Eds), Unemployment and Welfare. Toronto: Garamond Press.

Richmond, M. (1969, copyright). Friendly Visiting Among the Poor: A Handbook for Charity Workers. USA: Patterson Smith.

Sabatini, E. \& Nightingale, S. (1996). Welfare - No Fair: A Critical Analysis of Ontario's Welfare System (1885-1994). Canada: The Fraser Institute.

Schram, S. (1995). Words of Welfare: The Poverty of Social Science and the Social Science of Poverty. USA: University of Minnesota Press.

Schram, S. (2002). Praxis for the Poor. USA: New York University Press.

Siporin, M. (1992). Strengthening the Moral Mission of Social Work. In N. Reid \& P. Popple (Eds), The Moral Purposes of Social Work: The Character And Intentions of a Profession. Chicago, USA: Nelson-Hall Publishers, pp.71-94.

Social Assistance Review Committee (1988). Transitions. Toronto: Queen's Printer for Ontario.

Social Assistance Review Committee (1988). Transitions Summary. Toronto: Queen's Printer for Ontario.

Special Senate Committee on Poverty (2003). Poverty in Canada. Ottawa.

Stapleton, J. (2010). Municipal Social Services in Ontario: 1935-1940. \{Article: Publishing Pending for release in 2010$\}$

Stapleton, J. (2009). Close Encounters of the "Thirties" Kind. Ontario: Canadian Centre for Policy Alternatives.

Stapleton, J. (2008). The Last Recession Spook: A Very Curable Disease. Ontario: Canadian Centre for Policy Alternatives.

Stapleton, J. (2009). The Silence of the Lines: Poverty Reduction Strategies and the Crash of 2008. Ontario: Canandian Centre for Policy Alternatives.

Stephens, R. E. (1968). The Discipline of Social Work: A Critique. New York: Vantage Press.

Stephenson, M., Rondeau, G., Michaud, J. C. \& Fiddler, S. (2000). In Critical Demand: Social Work in Canada Volume 1 - Final Report. Ottawa: CASW. 
Stewart, R. (1981). Social Workers and Politics. Social Work, Volume 26, Number 4, July 1981, pgs. 267-273.

Struthers, J. (1994). The Limits of Affluence: Welfare in Ontario, 1920-1970. Toronto: University of Toronto Press.

Struthers, J. (1987). Shadows From the Thirties: The Federal Government and Unemployment Assistance, 1941-1956. In J. Ismael (ed.), The Canadian Welfare State: Evolution and Transition. Alberta: The University of Alberta Press, pp. 328.

Struthers, J. (1983). No Fault of their Own: Unemployment and The Canadian Welfare State 1914-1941. Toronto: University of Toronto Press.

Teare, R. (1981). Social Work Practice in a Public Welfare Setting: An Empirical Analysis. New York: Praeger Publishers.

Toren, N. (1972). Social Work: The Case of a Semi-Profession. USA: Sage Publications.

Weinroth, M. (1997). Deficitism and Neo-Conservatism in Ontario. In D. Ralph, A. Regimbald and N. St-Amand (Eds.), Open for Business Closed to People. Halifax: Fernwood Publishing, pp.54-67.

Wickenden, E. (1961). Public Welfare: Time for a Change. New York: New York School of Social Work.

Whitton, C. (1943). The Dawn of Ampler Life. Toronto: The MacMillan Company of Canada.

Williams, C. (1984). A History of the Ontario Ministry of Community and Social Services: 1930-1980 Decades of Service. Ontario: Ministry of Community and Social Services.

Winer, S. \& Shibata, H. (Eds.) (2002). Political Economy and Public Finance: The Role of Political Economy in the Theory and Practice of Public Economies. USA: Edward Elgar Publishing.

Woodroofe, K. (1966). From Charity to Social Work. Toronto: University of Toronto Press.

Woodsworth, D. E. (1965). An Approach to the Understanding of Poverty. The Social Worker, Volume 33, Number 3, July 1965, pgs. 153-156. 
Wyers, N. (1980). Whatever Happened to the Income Maintenance Line Worker? Social Work, Volume 25, Number 4, July 1980, pgs. 259-263.

Wyers, N. (1983). Income Maintenance and Social Work: A Broken Tie. Social Work, Volume 28, Number 4, July-August 1983, pgs. 261-268.

\section{Key Informant Interviews}

Drouin, H. (2009). Interview with A. Tutak (in-person) August 10, 2009, Whitby.

McNorgan, B. (2009). Interview with A. Tutak (by phone) August 14, 2009.

Moscovitch, A. (2009). Interview with A. Tutak. (in-Person) September 2, 2009, Ottawa.

Schuster, M. (2009). Interview with A. Tutak. (by phone) September 1, 2009.

Stapleton, J. (2010). Interview with A. Tutak (by phone) January 23, 2010.

Stewart, D. (2009). Interview with A. Tutak (in-person) September 4, 2009, Ottawa.

\section{Web Based References}

Canadian Association of Social Work Education (2010). Mission Statement. CASWE. Accessed April 17, 2010. http://www.caswe-acfts.ca/en/Mission Statement_24.html

Belanger, C. (2001). The Rowell-Sirois Report and Canadian Federalism during the Great Depression (1929-1939). Accessed December 27, 2009. Marianopolis College. http://faculty.marianopolis.edu/c.belanger/quebechistory/federal/rowell.htm

Rondeau, G. (2007). Challenges that Confront Social Work Education in Canada. Accessed January 4, 2008. CASW. http://www.personallMMSW school $\backslash$ CanandianAssociationofSocial WorkersRondeau

MacDougall, G. (2007). Social Work Practice: Another Look. Accessed January 4, 2008. CASW. 
http://www.personall\MSWschoollCanandianAssociationofSocialWorkersMacDougall

Jennissen, T., and C. Lundy (2006). Keeping Sight of Social Justice: 80 Years of Building CASW. Accessed April 10, 2010. CASW. http://www.casw-acts.ca/aboutcasw/building_e.pdf

Federal-Provincial- Territorial Directors of Income Support (2005). Social Assistance Statistical Report: 2005. Accessed January 2008.

http://www.sdc.gc.ca/en/cs/sp/sdc/socpol/page00.shtml

Distinguished Canadians (1972). Distinguished Canadians Television Program with interviewer John David Hamilton with Charlotte Whitton. Accessed February 2009.

http://archives.cbc.ca/politics/federal_politics/clips/15849/

CBC News (1995). CBS News Report with host Peter Mansbridge and reporter Denise Harrington, broadcast date October 20, 1995. Accessed September 2009. http://archives.cbc.ca/politics/provincial territorial politics/clips/12459/.

Morier, R.. Style and Substance; The Career of Charlotte Whitton. Accessed February 6,2009 . York University. http://74.125.95.132/search?q=cache:FPsX0N094awJ:pi.library.yorku.ca/ojs/inde x.php/cws/article/view/14130/13183+charlotte+whitton\&hl=en\&ct $=$ clnk\&cd $=10$ $\& \mathrm{gl}=\mathrm{ca}$.

Ontario College of Social Workers and Social Service Workers (2010). Membership Information. OCSWSSW. Accessed April 18, 2010. http://www.ocswssw.org/en/about ssw.htm 